\title{
Análise e implementação de métodos para a caracterização de eletretos termo-formados
}

\author{
Ruy Alberto Pisani Altafim
}

Dissertação apresentada à Escola de Engenharia de São Carlos da Universidade de São Paulo, como parte dos requisitos para obtenção do título de Mestre em Engenharia Elétrica

Orientador: Prof. Dr. Luiz Gonçalves Neto 
Dedicatória

Este trabalho é dedicado à comunidade científica, que emprega o seu tempo no avanço da ciência. 
Agradecimentos

A realização deste trabalho é fruto da contribuição de várias pessoas e entidades governamentais. Com isso não poderia deixar de agradecer a Capes e a Fipai, pelo incentivo financeiro, meus amigos e familiares, em especial minha noiva Letícia, meu orientador Luiz Gonçalves Neto, o professor Heitor C. Basso por trabalhar como co-orientador neste trabalho, o técnico Rui Bertho pelo seu maravilhoso trabalho de oficina, e a Deus que sempre esteve presente. 



\section{Resumo}

Altafim R. A. P. Análise e implementação de métodos para a caracterização de eletretos termo-formados. São Carlos, 2005 Dissertação de Mestrado - Escola de Engenharia de São Carlos, Universidade de São Paulo.

O objetivo deste trabalho é aplicar os métodos de medidas dinâmicos dos polímeros piezoelétricos na caracterização dos eletretos termo-formados de Teflon-FEP desenvolvidos no Laboratório de Medidas e Padrões da Escola de Engenharia de São Carlos (EESC) - Universidade de São Paulo (USP). Para isso, foram implementados os métodos dinâmico direto, acústico direto, acústico inverso e interferométrico. Também foram desenvolvidos neste trabalho dois aplicativos computacionais de controle e aquisição de dados dos equipamentos de medidas, Lock-in SR510, osciloscópio Tektronix TDS 210 e gerador de áudio Tektronix CFG253. Esta caracterização é importante porque visa utilizar os eletretos termo-formados como dispositivos eletromecânicos para realizar inúmeras aplicações nas áreas da robótica, da bioengenharia e nas medidas elétricas e mecânicas. A vantagem dos eletretos termo-formados com relação aos demais polímeros piezoelétricos, é que estes são estruturas homogêneas, com grande reprodutibilidade no processo de fabricação e apresentam altos coeficientes piezoelétricos.

Palavras-Chave: Polímeros piezoelétricos, eletretos e métodos de caracterização de eletretos. 



\section{Abstract}

Altafim R. A. P. Analysis and implementation of methods for the characterization of thermo-formed electrets. São Carlos, 2005 Masters Dissertation - Escola de Engenharia de São Carlos, Universidade de São Paulo.

The aim of this work is to apply the dynamical measurement methods of piezoelectric polymers into the characterization of thermo-formed electrets of Teflon-FEP developed in the Laboratory of Measurements and Standards of the School of Engineering of São Carlos (EESC) - University of São Paulo (USP). The direct dynamical, direct acoustic, inverse acoustic and interferometric methods are aplyed to implement these measurements. Two routines were also developed to control and realize the data acquisition of the measurement equipments Lock-in SR510, Tektronix TDS-210 oscilloscope and Tektronix CFG-253 function generator. The characterization of these termo-formed electret is important because they can be used into electromechanical devices for innumerable applications in the areas such as robotics, bioengineering and electric and mechanic measurements. The advantage of the thermo-formed electrets, compared to all others piezoelectric polymers, is that they are homogeneous structures with reproducible fabrication process, to presenting high piezoelectric coefficients.

Key-Words: Piezoelectric polymers, electrets and electrets characterization methods. 


\section{Sumário}

Resumo v v

Abstract vii

Lista de Figuras $\quad$ xi

$\begin{array}{ll}\text { Lista de Tabelas } & \text { Xv }\end{array}$

$\begin{array}{ll}\text { Lista de Abreviaturas e Siglas } & \text { xvii }\end{array}$

Lista de Símbolos $\quad$ xix

1 Introdução 1

1.1 A evolução da piezoeletricidade nos polímeros . . . . . . . . . . . . . . 1

1.2 Teoria da piezoeletricidade e dos eletretos . . . . . . . . . . . 5

1.3 Aplicações . . . . . . . . . . . . . . . . . . . . . . . . . . . . 12

2 Principais Métodos de Medida da Piezoeletricidade 15

2.1 Medida da piezoeletricidade em biopolímeros . . . . . . . . . . . 15

2.2 Métodos de medida da piezoeletricidade . . . . . . . . . . . . . 16

2.2.1 Método direto de medida da piezoeletricidade . . . . . . . . . 16

2.2.2 Métodos inversos de medida da piezoeletricidade . . . . . . . . . 21

3 Caracterização dos eletretos termo-formados $\quad 27$

3.1 Sistema mecânico direto . . . . . . . . . . . . . . . . . . . . . 28

3.2 Interferometria . . . . . . . . . . . . . . . . . . . . 35

3.3 Acústico direto e inverso . . . . . . . . . . . . . . . . . . . 35

3.3 .1 Método acústico direto . . . . . . . . . . . . . 36

3.3 .2 Método acústico inverso . . . . . . . . . . . . . . . . . 37

4 Programas Computacionais para Aquisição de Dados 39 
4.1 Sistema de Aquisição Lock-in SR510 . . . . . . . . . . . . . . . . . . . 39

4.2 Sistema de Aquisição TDS210-SR510 . . . . . . . . . . . . . . . . . . . 44

$\begin{array}{lll}5 & \text { Resultados } & 47\end{array}$

5.1 Método acústico em ambiente silencioso . . . . . . . . . . . . . 47

5.1 .1 Método acústico direto . . . . . . . . . . . . . . . . 48

5.1 .2 Método acústico inverso . . . . . . . . . . . . . . . . . . . . . 49

5.2 Método acústico em câmara fechada . . . . . . . . . . . . . . . . . . . 50

5.3 Comparação entre uma e múltiplas bolhas pelo método direto . . . . . . 54

5.4 Comparação entre uma e múltiplas bolhas pelo método inverso . . . . . 55

5.5 Outros resultados . . . . . . . . . . . . . . . . . 5 56

6 Conclusões $\quad 57$

$\begin{array}{ll}\text { Referências Bibliográficas } & 59\end{array}$

$\begin{array}{ll}\text { A } & 65\end{array}$

A.1 Teoria do microfone de eletreto . . . . . . . . . . . . . 65

A.2 Curvas de ponderação em freqüência do decibelímetro . . . . . . . . . . 67 


\section{Lista de Figuras}

1.1 Imagem microscópica de um filme de polipropileno de $70 \mu \mathrm{m}$ de espessura (HILLENBRAND \& SESSLER, 2004) . . . . . . . . . . . . . . . . 3

1.2 Amostra com dois filmes de Teflon-FEP coladas com tinta sintética. . . 4

1.3 Bolhas formadas pela tinta sintética entre os filmes. . . . . . . . . . . 4

1.4 Modelo do novo sistema de preparo de amostras. . . . . . . . . . . . . 4

1.5 Evolução dos transdutores de multiplas camadas de Teflon-FEP. . . . . 5

1.6 Micro bolhas de ar, formadas com o novo método. . . . . . . . . . 5

1.7 Formação da polarização induzida através da pressão no cristal. . . . . . 6

1.8 Processo de polarização que consiste em aquecer o material durante a aplicação de um campo elétrico. . . . . . . . . . . . . . . . . 7

1.9 Diferentes ângulos de aplicação de força em um material piezoelétrico. 8

1.10 Representação do efeito piezoelétrico em polímeros porosos (GERHARD-

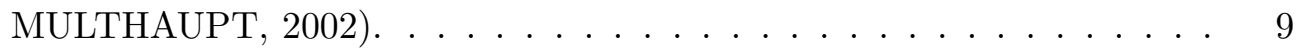

1.11 Representação esquemática do microfone de eletreto (SESSLER, 1987). 9

1.12 Representação esquemática do circuito RC do transdutor. . . . . . . . . 10

1.13 Teclado a base de filme polimérico (SCREENTEC, 2006). . . . . . . . 12

2.1 Modelo esquemático do processo quase-estático. . . . . . . . . . . . . 17

2.2 Equipamento para exercer uma descompressão mais uniforme na amostra $(\operatorname{LIMA}, 2005) . \ldots \ldots \ldots \ldots \ldots$ 
2.3 Sistema de medida dinâmico com shaker (HILLENBRAND \& SESSLER,

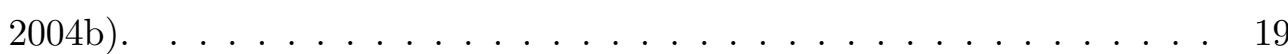

2.4 Sistema de medida dinâmico utilizando pressão pneumática (KIM \&

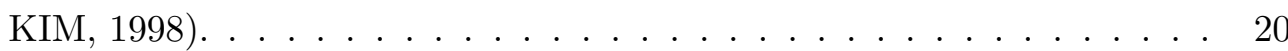

2.5 Representação esquemática do sistema acústico direto. . . . . . . . . . . . 21

2.6 Sistema de medida dinâmico acústico inverso (WEINHOLD et al., 2000). 22

2.7 Sistema de medida dinâmico com acelerômetro. . . . . . . . . . . . . 22

2.8 Interferômetro de Michelson. . . . . . . . . . . . . . . . . . . . 24

2.9 Ondas de interferência criadas pelo interferômetro. . . . . . . . . . . . . 24

2.10 Montagem experimental utilizando um interferômetro (FUKADA, 2000). 25

3.1 Método de medida por vibração mecânica. . . . . . . . . . . . . . . . 28

3.2 Representação esquemática do sistema. . . . . . . . . . . . . . . 28

3.3 Relação entre a força exercida pelo alto-falante e a corrente elétrica. . . 30

3.4 Resultados obtidos com o sistema automatizado (ALTAFIM et al., 2005). 31

3.5 Sistema de medida dinâmico com o alto-falante invertido. . . . . . . . . 32

3.6 Amostra sem deformação estrutural. . . . . . . . . . . . . . . . . . . . 32

3.7 Amostra com deformação estrutural. . . . . . . . . . . . . . . . . . . 32

3.8 Amostra homogênea $-1^{\mathrm{o}}$ medida. . . . . . . . . . . . . . . . . 33

3.9 Amostra homogênea $-2^{\text {o }}$ medida. . . . . . . . . . . . . . . . . . 33

3.10 Amostra com falhas estruturais $-1^{\mathrm{o}}$ medida. . . . . . . . . . . . . . 33

3.11 Amostra com falhas estruturais $-2^{\circ}$ medida.. . . . . . . . . . . 33

3.12 Amostra descarregada. . . . . . . . . . . . . . . . . . 34

3.13 Amostra carregada. . . . . . . . . . . . . . . . . . 34

3.14 Primeira medida com a amostra $(12 / 09 / 2005) . \ldots \ldots 34$

3.15 Segunda medida após uma semana $(19 / 09 / 2005) \ldots \ldots$. . . . . . . . . . 34

3.16 Interferômetro de Michelson. . . . . . . . . . . . . . . . . 35 
3.17 Método de medida acústico direto. . . . . . . . . . . . . . . . . 36

3.18 Método de medida acústico inverso. . . . . . . . . . . . . . . . . . 37

3.19 Foto da caixa acústica. . . . . . . . . . . . . . . . . . . . . . . 38

3.20 Foto da caixa acústica. . . . . . . . . . . . . . . . . . . . . . . 38

4.1 Tela principal do programa de aquisição. . . . . . . . . . . . . . . . . 40

4.2 Tela de configuração da comunicação serial. . . . . . . . . . . . . . . . . 41

4.3 Coleta de dados utilizando o oscilador interno Lock-in. . . . . . . . . . . 41

4.4 Tela de configuração para aquisição de dados com o gerador de frequência. 42

4.5 Botão para aquisição de dados utilizando somento o Lock-in. . . . . . . 43

4.6 Botão de aquisição utilizando o gerador de frequência. . . . . . . . . . . . 43

4.7 Botão para plotar os resultados em forma de gráficos. . . . . . . . . . . 43

4.8 Botão para exportar os dados para o Microsoft Excel. . . . . . . . . . . 43

4.9 Tabela para exibição dos resultados coletados. . . . . . . . . . . . . . . . 43

4.10 Tela principal do Sistema de Aquisição TDS210-SR510. . . . . . . . . . 44

5.1 Formato da amostra utilizada na caracterização acústica . . . . . . . . . 48

5.2 Relação entre sinal de saída em $m V$ do tweeter pela freqüência. . . . . . 48

5.3 Relação entre sinal de saída em $d B$ do tweeter pela freqüência. . . . . . 48

5.4 Relação entre a razão do sinal da amostra $m V / P a$ pela freqüência no método acústico direto. . . . . . . . . . . . . . . . . . . . . . . 49

5.5 Relação entre a freqüência e a pressão acústica exercida pela amostra no método acústico inverso. . . . . . . . . . . . . . . . . . . . . . . 49

5.6 Relação entre freqüência e pressão acústica do tweeter ST300 da Selenium $($ SELENIUM, 2006) . . . . . . . . . . . . . . . . 50

5.7 Relação entre freqüência e pressão acústica do tweeter ST300 da Selenium no sistema. . . . . . . . . . . . . . . . . . . . 50

5.8 Amostra de Teflon-FEP com uma bolha de $4 \mathrm{~mm}$ de diâmetro. . . . . . 51 
5.9 Relação sinal da amostra pelo sinal do microfone em função da freqüência para uma amostra com uma única bolha. . . . . . . . . . . . . . . 51

5.10 Relação entre a resposta da amostra em $m V$ pela freqüência de várias amostras com uma única bolha. . . . . . . . . . . . . . . . . . . . . . 52

5.11 Relação do sinal da amostra em função da freqüência de várias amostras com uma única bolha. . . . . . . . . . . . . . . . . . . . . . . 52

5.12 Relação dos sinais das amostras 3 e 4 em função da freqüência. . . . . . 53

5.13 Resposta da amostra com múltiplas bolhas pelo método acústico direto. 54

5.14 Resposta da amostra com múltiplas bolhas pelo método acústico inverso. 54

5.15 Resposta das amostras com múltiplas bolhas e das amostras com uma bolha pelo método direto. . . . . . . . . . . . . . . . 55

5.16 Resposta das amostras com múltiplas bolhas e das amostras com uma bolha pelo método inverso. . . . . . . . . . . . . . . 55

A.1 Representação esquemática do microfone de eletreto. . . . . . . . . . . 65

A.2 Curvas de ponderação em freqüência. . . . . . . . . . . . . . . 67 


\section{Lista de Tabelas}

3.1 Resultado da calibração do sistema. . . . . . . . . . . . . . . . 29

3.2 Resultados obtidos na calibragem dinâmica. . . . . . . . . . . . . . 30 


\section{Lista de Abreviaturas e Siglas}

PP Polipropileno

FEP Fluoretilenopropileno

PTFE Politetrafluoretileno

PVDF Polifluoreto de vinilideno

AF Flouropolímeros Amorfos

MDF Medium Density Fiberboard

PZT Titanato-zirconato de chumbo

PVC Policloreto de vinila

DC Corrente contínua

AC Corrente alternada

USP Universidade de São Paulo

EESC Escola de Engenharia de São Carlos 


\title{
Lista de Símbolos
}

\author{
$\Omega \quad$ Ohm - unidade de resistência elétrica \\ $\mathrm{Pa} \quad$ Pascal - unidade de medida de pressão \\ $d B \quad$ decibel - nível de potência \\ $\mathrm{Hz} \quad$ Hertz - unidade de medida da freqüência \\ $N \quad$ Newton - unidade de medida da força \\ F $\quad$ Faraday - unidade de medida da capacitância \\ ${ }^{\circ} \mathrm{C}$ Graus Celsius - unidade de medida da temperatura \\ $d_{33} \quad$ coeficiente piezoelétrico \\ E campo elétrico \\ V Volts \\ $m V \quad$ miliVolt \\ $n F \quad$ nano Faraday \\ $\mathrm{pm} / V$ picometro por Volt \\ $p C / N$ picoCoulomb por Newton \\ cm centímetros \\ $\mathrm{mm}$ milímetros \\ $\dot{V} \quad$ tensão fasorial \\ $\dot{I} \quad$ corrente fasorial
}




\section{Capítulo 1}

\section{Introdução}

Este trabalho tem por finalidade analisar, implementar e desenvolver métodos para a caracterização de eletretos de polifluoretileno (Teflon-FEP) com bolhas de ar macroscópicas (LIMA, 2005). Para a implementação de metodologias e técnicas de caracterização destes novos eletretos, faz-se necessária uma clara compreensão do efeito piezoelétrico nos polímeros, objetivo deste capítulo. Nesta caracterização, um novo conceito de piezoeletricidade é abordado.

\subsection{A evolução da piezoeletricidade nos polímeros}

Pesquisas relacionando cargas elétricas a materiais dielétricos, vêm sendo reportadas desde o início do século XIX, quando Charles Augustin Coulomb elaborou as primeiras hipóteses sobre a presença de cargas elétricas superficiais em substâncias sólidas, devido a aplicação de pressão mecânica. Essas teorias foram comprovadas em 1880 pelos irmãos Curie, através da descoberta de um efeito que relacionava o surgimento de cargas elétricas com a aplicação de um estresse mecânico, em cristais. Esse efeito foi denominado por Hermann Hankel de "piezoeletricidade" em 1881 (TRAINER, 2003).

Também em 1881 Gabriel Lipmann propôs a existência do efeito inverso, ou seja, que uma deformação mecânica ocorreria mediante aplicação de um sinal elétrico. Logo em seguida, no mesmo ano, esse efeito também foi comprovado pelos irmãos Curie. Com isso, a piezoeletricidade ficou definida como a propriedade que alguns materiais 
possuem de gerar cargas elétricas superficiais quando submetidos a esforços mecânicos. Seu efeito inverso, ou seja, a capacidade de alguns materiais apresentarem deformações mecânicas quando uma tensão elétrica é aplicada, também faz parte dessa definição (BALLATO, 1996).

A descoberta da piezoeletricidade nos cristais, criou condições para o desenvolvimento de diversas aplicações como, por exemplo, o sonar utilizado durante a Segunda Guerra Mundial na detecção de submarinos. Embora o efeito piezoelétrico nos cristais estivesse bem compreendido, ele só foi detectado nos polímeros em 1969 por Kawai. Esta descoberta foi embasada nos estudos realizados na década anterior por Yasuda e por Fukada, com pedaços de madeira seca e com fibras de colágeno respectivamente (FUKADA, 2000). Kawai em seus estudos com polímeros, encontrou o efeito piezoelétrico em filmes polarizados de Fluoreto de Polivinilideno (PVDF), com valores de coeficientes piezoelétricos $d_{33}$ em torno de $30 \mathrm{pC} / \mathrm{N}$, superiores aos valores descobertos por Fukada de 2,0 pC/N no ano de 1957 (FUKADA, 2000).

Após a descoberta da piezoeletricidade no PVDF, vários outros polímeros passaram a ser estudados na tentativa de se obter coeficientes piezoelétricos maiores. Nesses estudos, percebeu-se que cada tipo de polímero possui uma particularidade elétrica como, por exemplo, a capacidade dos polímeros à base de silicone e dos tratados com flúor de armazenarem cargas elétricas, e das poliamidas ímpares e aromáticas de apresentarem elevados coeficientes piezoelétricos (GERHARD-MULTHAUPT, 2002).

As pesquisas também contribuíram para o desenvolvimento de novos materiais poliméricos com características específicas e aspectos industriais superiores aos do PVDF. Este é o caso dos copolímeros amórficos de tetrafluoretileno (Teflon ${ }^{T M} \mathrm{AF}$ ), que possuem altos coeficientes piezoelétricos, maior estabilidade térmica e podem ser utilizados em aplicações ópticas, por serem transparentes (GüNTHER et al., 1993); (GERHARD-MULTHAUPT, 2002).

Na década de 80 surgiram os polímeros porosos e celulares, como o polipropileno (PP). Estes polímeros além de serem mais leves e menos rígidos que os demais polímeros, apresentam elevados coeficientes piezoelétricos $(800 \mathrm{pC} / \mathrm{N})$, quando submetidos a processos de polarização (GERHARD-MULTHAUPT, 2002). Um exemplo microscópico do PP pode ser visto na figura 1.1. 


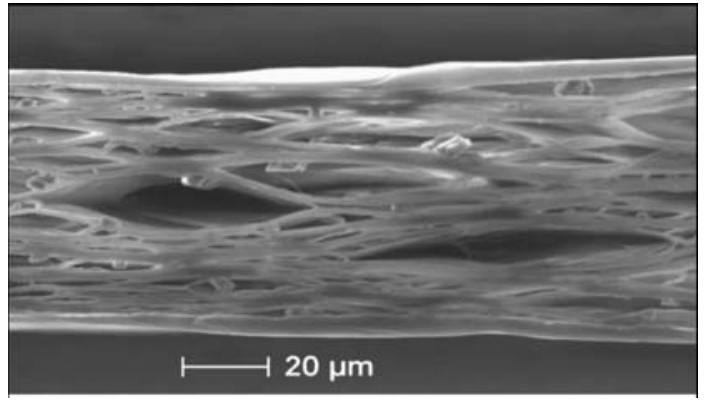

Figura 1.1: Imagem microscópica de um filme de polipropileno de $70 \mu \mathrm{m}$ de espessura (HILLENBRAND \& SESSLER, 2004).

A descoberta dos altos coeficientes piezoelétricos encontrados nos polímeros porosos, direcionou os estudos da piezoeletricidade para a análise das cavidades internas desses polímeros. Esses estudos mostraram que o efeito piezoelétrico era resultante da polarização das bolhas de ar, na qual cargas positivas eram aprisionadas nas superfícies das bolhas e cargas negativas na parte inferior.

Esse efeito, se analisado em escala microscópica diferencia-se totalmente do efeito dos cristais, pois o efeito das bolhas se assemelha a capacitores de placas paralelas separados por um dielétrico, que neste caso é o ar. Com isso, pode-se explicar o efeito através da teoria do microfone de eletreto, melhor descrita no subitem 1.2. Para essa diferença entre os fenômenos sugeriu-se um novo termo, o de "pseudo-piezoeletricidade", para se referir ao efeito nos polímeros porosos (GERHARD-MULTHAUPT, 2002).

Embora o efeito das estruturas das bolhas fosse a principal causa da alta piezoeletricidade observada, as pesquisas foram direcionadas para o desenvolvimento de estruturas com múltiplas camadas de polímeros porosos com diferentes densidades, e apresentaram valores piezoelétricos acima dos 800 pC/N (GERHARD-MULTHAUPT, 2002).

Seguindo uma outra linha de pesquisa com base apenas nas bolhas internas, desenvolveu-se uma estrutura polimérica utilizando dois filmes de fluoretilenopropileno (Teflon-FEP) e tinta sintética (ALTAFIM et al., 2003). Para o desenvolvimento dessas estruturas, foi utilizado spray de tinta sintética para borrifar gotículas de tinta, de maneira a criar espaços de ar entre os filmes de Teflon-FEP. Estas gotículas de tinta também serviram para unir os filmes como mostram as figuras 1.2 e 1.3 (RODRIGUES, 
2003).

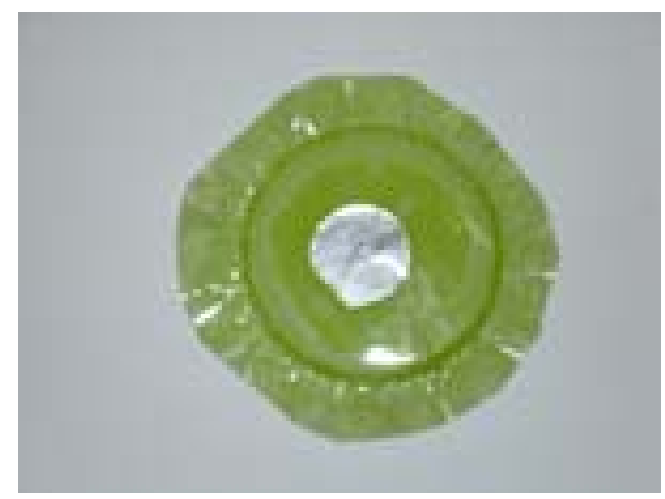

Figura 1.2: Amostra com dois filmes de Teflon-FEP coladas com tinta sintética.

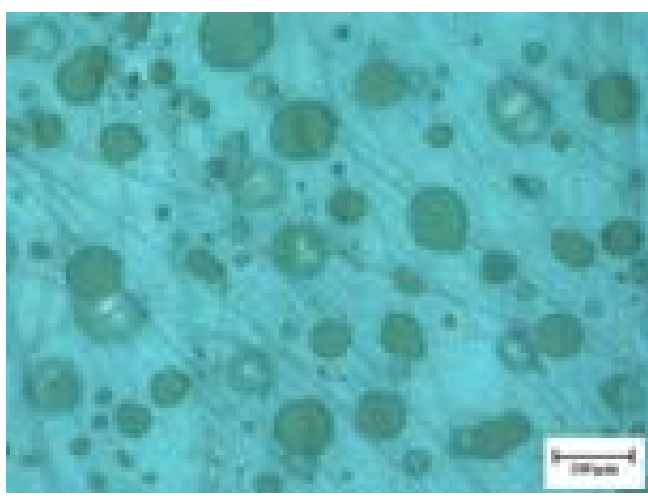

Figura 1.3: Bolhas formadas pela tinta sintética entre os filmes.

As amostras montadas com essa técnica, foram carregadas pelo método impulsivo desenvolvido por (ALTAFIM et al., 1992), e apresentaram ótimos resultados. Essa mudança de perspectiva focando as bolhas mostrou que é possível criar estruturas com altos índices piezoelétricos e com materiais termicamente mais estáveis.

No entanto, esta técnica resultou em amostras com baixa resistência mecânica devido a característica antiaderente do Teflon-FEP (DUPONT, 2005); (LIMA, 2005). Para aumentar a resistência mecânica e a confiabilidade dos resultados, foi desenvolvido um novo método para produzir amostras de Teflon-FEP, utilizando eletrodos metálicos aquecidos independentemente e uma bomba a vácuo para deformar um dos filmes, formando múltiplas bolhas de ar entre os filmes de Teflon-FEP. A figura 1.4 mostra um esquema gráfico desse mecanismo (ALTAFIM et al., 2005).

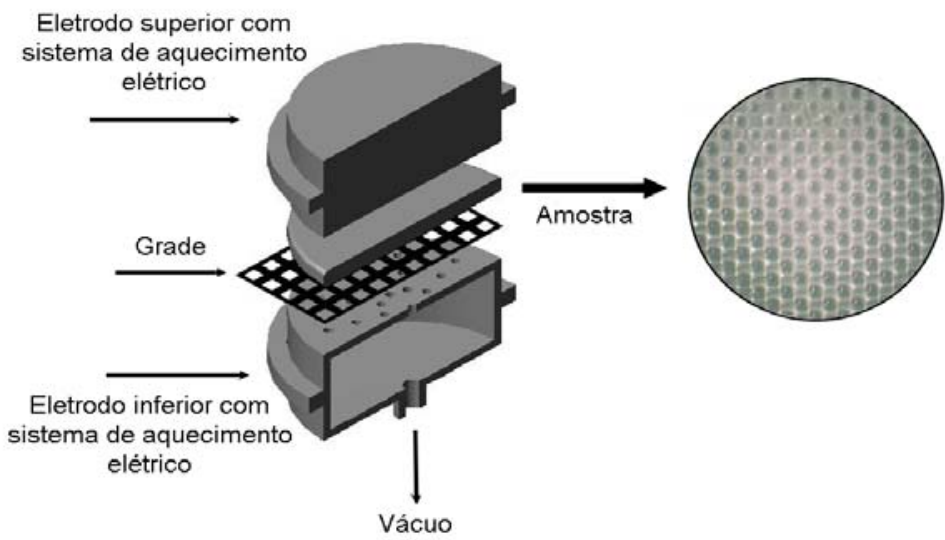

Figura 1.4: Modelo do novo sistema de preparo de amostras. 
Esse novo método de fabricação permitiu controlar a forma e o tamanho das bolhas, conforme mostram as figuras 1.5 e 1.6 e também possibilitou fundir os filmes, melhorando a adesão entre eles. As amostras produzidas por esse sistema passaram a receberam o nome de eletreto termo-formados, pelo fato do processo de produção ser aquecido.

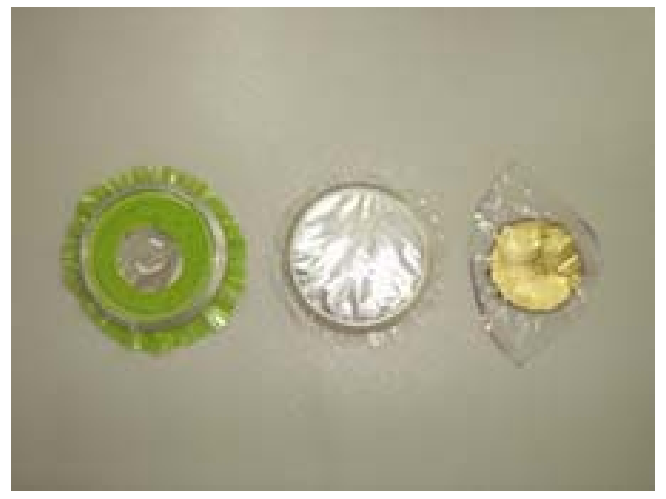

Figura 1.5: Evolução dos transdutores de multiplas camadas de Teflon-FEP.

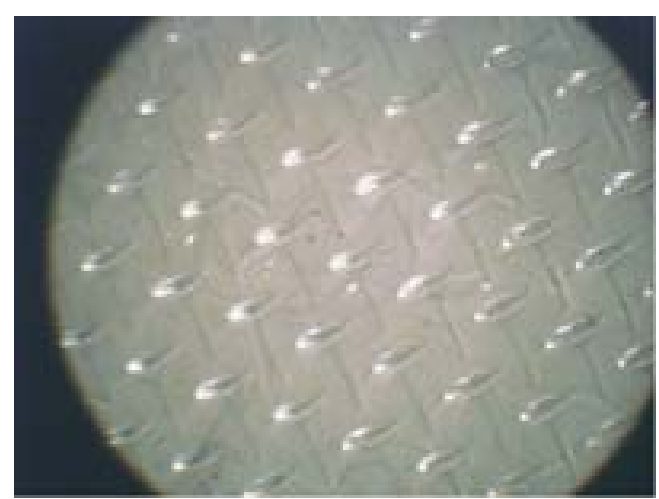

Figura 1.6: Micro bolhas de ar, formadas com o novo método.

Recentemente um artigo foi publicado na revista Applied Physics A (ZHANG et al., 2006) referenciando o artigo (ALTAFIM et al., 2005) e apresentando um sistema similar para a produção de bolhas de ar em filmes de Teflon-FEP e de Politetrafluoretileno (PTFE). Essa publicação mostra que as pesquisas com polímeros piezoelétricos tendem a seguir essa linha de pesquisa.

A seguir são apresentados os conceitos teóricos da piezoeletricidade e dos eletretos, para compreender como os eletretos termo-formado realmente funcionam e como o conceito de piezoeletricidade evoluiu para chegar nestas amostras.

\subsection{Teoria da piezoeletricidade e dos eletretos}

Os materiais naturalmente piezoelétricos como alguns cristais, a exemplo, a Quartzo e algumas cerâmicas, como o titanato zirconato de chumbo (PZT), possuem uma organização molecular bipolar que se repete por todo o material formando uma estrutura polarizada. A polarização natural das moléculas é a principal responsável pela indução de cargas elétricas superficiais que contribuem para o efeito piezoelétrico (BALLATO, 1995). 
As cargas elétricas superficiais possuem sinais elétricos contrários aos da polarização, e mantem todo o conjunto, cargas superficiais e material polarizado em estado de equilíbrio (HALLIDAY \& RESNICK, 1975). Quando um material piezoelétrico sofre a ação de uma força externa, ocorre uma variação instantânea na polarização $\vec{P}$, alterando as cargas superficiais, que tendem a se reorganizar.

Posicionado esses materiais entre dois eletrodos ligados a um amperímetro de baixa resistência interna é possível observar um fluxo de corrente instantâneo, durante a aplicação da força externa (LANG, 2005) como mostra a figura 1.7.
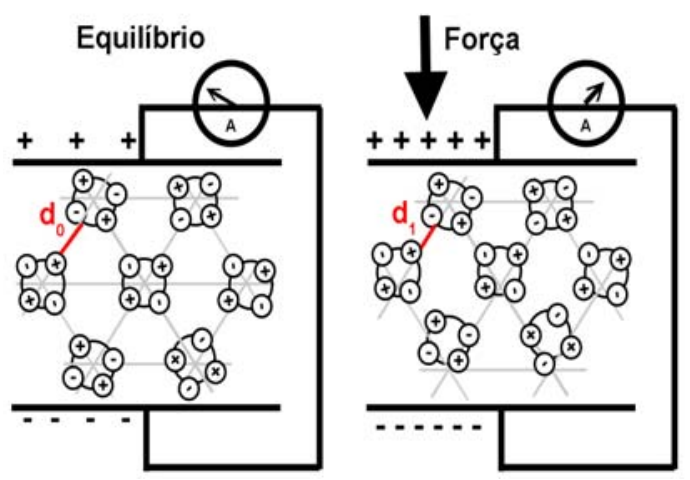

Figura 1.7: Formação da polarização induzida através da pressão no cristal.

O equacionamento a seguir mostra a relação da polarização com a piezoeletricidade.

$$
\vec{D}=\varepsilon_{0} \vec{E}+\vec{P}
$$

nessa equação $\vec{D}$ representa o vetor densidade de fluxo elétrico, $\varepsilon_{0}$, a permissividade do vácuo, $\vec{E}$, o campo elétrico e $\vec{P}$ o vetor de polarização.

A polarização $\vec{P}$, para materiais isotrópicos e homogêneos em um temperatura $T_{0}$, pode ser definida pela expressão 1.2 , se o campo elétrico for zero e a tensão mecânica $X=0$

$$
\vec{P}=\varepsilon_{0} \chi \vec{E}+d X+p\left(T-T_{0}\right)
$$

onde $\chi$ é a susceptibilidade elétrica do material e $d$ e $p$ são as constantes piezoelétrica e piroelétrica, que se relacionam com a variação de força e de temperatura, respectivamente. 
No entanto, a maioria dos polímeros não possuem polarização molecular natural, mas alguns deles, como o PVDF, podem ser polarizados através de processos de polarização. O método de polarização mais utilizado consiste em aplicar um campo elétrico de polarização de alta tensão DC, definido por $\left(E_{p}\right)$ através do material a uma temperatura $\left(T_{p}\right)$ elevada durante um certo tempo de polarização $\left(t_{p}\right)$. Após o período de tempo $t_{p}$ o filme é resfriado à temperatura ambiente mantendo-se o campo elétrico, conforme mostra a figura 1.8. O polímero polarizado, agora capaz de induzir cargas elétricas superficiais passa a ser denominado eletreto (WADA \& HAYAKAWA, 1976).

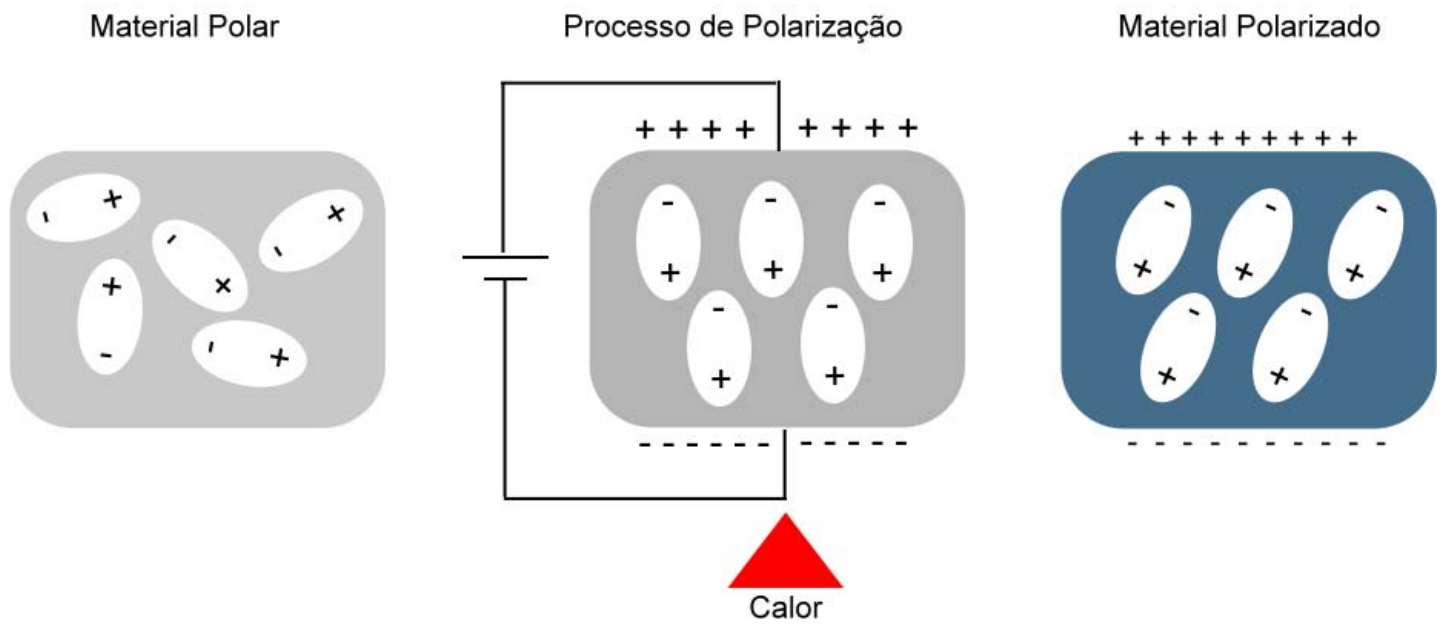

Figura 1.8: Processo de polarização que consiste em aquecer o material durante a aplicação de um campo elétrico.

O processo de polarização dos polímeros porosos e celulares diferencia-se do processo descrito, pois além de não ser necessário aquecer o material, o campo elétrico de alta intensidade aplicado, tem a função de separar as cargas elétricas existentes nas cavidades dos polímeros porosos, transformando-as em grandes dipolos através de descargas elétricas internas e não de alinhar as moléculas bipolares (GERHARDMULTHAUPT, 2002).

A polarização, dos polímeros porosos e dos eletretos termo-formados, ocorre preferencialmente sempre no sentido do campo elétrico aplicado, o que não ocorre nos cristais, nas cerâmicas e nem nos polímeros polares, que possuem diversas geometrias e ângulos de polarização.

Para representar essas variações de polarização foi criado uma notação nomeada de constantes piezoelétricas de carga $d_{i j}$, que indica a direção da polarização e o 
sentido que a força externa deve ser aplicada para se obter o maior valor do coeficiente piezoelétrico (APC INTERNATIONAL, 1998).

Estas constantes foram representada por Voigt na forma de uma matriz (TRAINER, 2003), dada por:

$$
\left(\begin{array}{llllll}
d_{11} & d_{12} & d_{13} & d_{14} & d_{15} & d_{16} \\
d_{21} & d_{22} & d_{23} & d_{24} & d_{25} & d_{26} \\
d_{31} & d_{32} & d_{33} & d_{34} & d_{35} & d_{36}
\end{array}\right)
$$

Na qual a leitura dos índices das constantes piezoelétricas de carga $d_{i j}$ deve ser interpretada da seguinte maneira: o primeiro índice $(i)$ indica a direção da polarização do material quando o campo elétrico externo é igual a zero, e o segundo índice $(j)$ indica o sentido da pressão externa aplicada (APC INTERNATIONAL, 1998). A figura 1.9 mostra os números que representam essas direções.

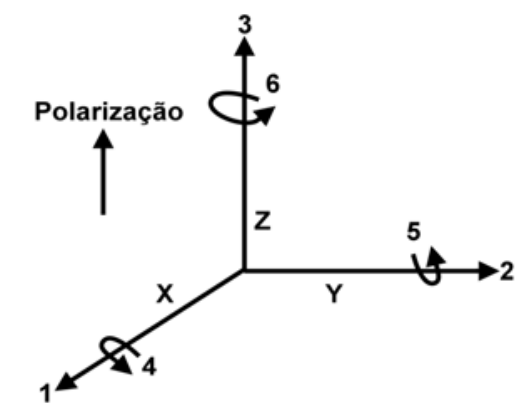

Figura 1.9: Diferentes ângulos de aplicação de força em um material piezoelétrico.

Como a polarização dos polímeros porosos e dos eletretos termo-formados está sempre alinhada na direção do campo, a aplicação da força externa também ocorre na mesma direção, por isso utiliza-se apenas o coeficiente $d_{33}$ na caracterização desses materiais.

A figura 1.10 mostra uma representação esquemática da polarização e do efeito piezoelétrico em um polímero poroso, na qual é possível perceber a orientação das cargas. Ao se pressionar o polímero ocorre uma variação na concentração de cargas superficiais nos eletrodos superiores e inferiores, produzindo uma diferença de tensão instântanea.

O resultado macroscópico da diferença de potencial elétrico observado nesse 

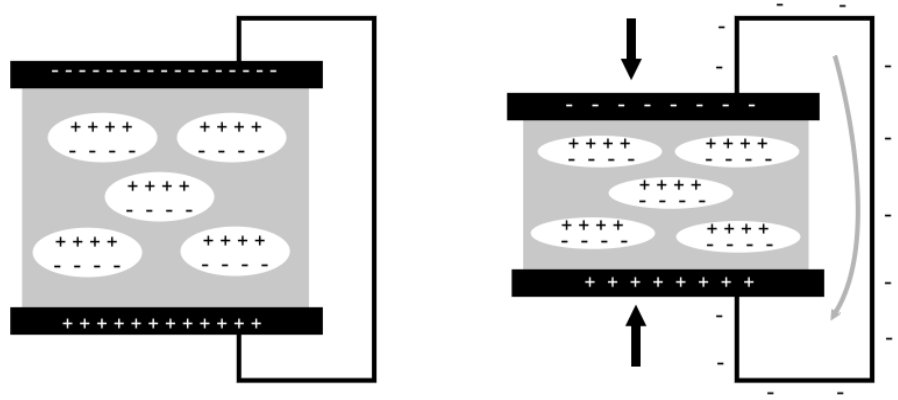

Figura 1.10: Representação do efeito piezoelétrico em polímeros porosos (GERHARDMULTHAUPT, 2002).

efeito é similar a piezoeletricidade encontrada nos cristais, cerâmicas e nos polímeros polares. Nesses materiais as cargas elétricas são induzidas na superfície dos eletrodos e uma variação na polarização cria uma diferença de potencial entre os eletrodos. No entanto microscopicamente os "dipolos artificiais" operam como transdutores de eletretos miniaturizados (GERHARD-MULTHAUPT et al., 2000).

Os transdutores de eletretos, como os microfones, podem ser produzidos com um dielétrico sólido eletricamente carregado e metalizado, formando um diafragma separado de uma placa metálica por uma camada de ar. Isso cria um efeito similar ao das bolhas, pois neste caso também ocorre a separação de cargas elétricas por espaço de ar. Uma representação esquemática do microfone de eletreto encontra-se na figura 1.11 .

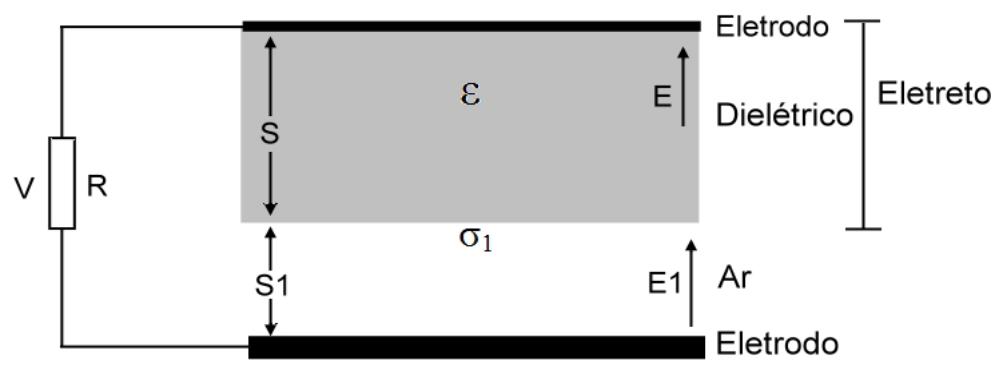

Figura 1.11: Representação esquemática do microfone de eletreto (SESSLER, 1987).

Nesta imagem as dimensões verticais foram ampliadas para facilitar a explicação, pois nos casos reais a distância entre o espaço de ar e o dielétrico é pequena (aproximadamente $1 \mu \mathrm{m}$ ). O dielétrico metalizado de um lado e a placa metálica estão ligados por um resistor $R$. A densidade de carga do eletreto considerada constante está 
representada na figura 1.11 por $\sigma_{1}$ e é responsável pela geração do campo elétrico na camada de ar $E_{1}$ (SESSLER, 1987).

Em condições de circuito aberto, ou seja, $R$ infinita o campo elétrico e a as cargas induzidas permanecem constantes. No caso de uma onda sonora atingir o diafragma, ocorre uma deflexão de amplitude $\hat{S}$ alterando a espessura da camada de ar $S_{1}$ e produzindo uma amplitude de tensão de saída $\hat{V}=-E_{1} \hat{S}$ com valor independente da freqüência, como mostra a equação 1.3 (SESSLER, 1987).

$$
\hat{V}=\begin{gathered}
S \hat{S} \sigma_{1} \\
\epsilon_{0}\left(S+\epsilon S_{1}\right)
\end{gathered}
$$

na qual $S$ é a espessura do dielétrico, $S_{1}$ é espessura da camada de ar, $\epsilon$ é permissividade relativa do dielétrico e $\epsilon_{0}$ é a permissividade do vácuo. O desenvolvimento da equação 1.3 encontra-se no apêndice A.

Para uma resistência $R$ finita tem-se um circuito do tipo resistor-capacitor (RC) apresentado na figura 1.12 e a relação entre a corrente elétrica $I$ do circuito e a tensão $V$ no resistor $R$ é dada na forma fasorial pela equação 1.4.

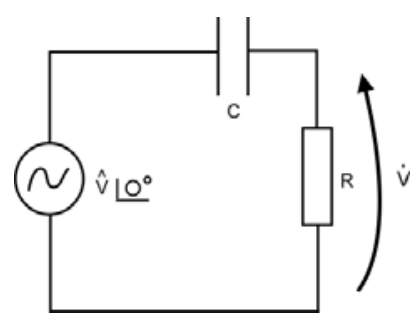

Figura 1.12: Representação esquemática do circuito RC do transdutor.

$$
\dot{V}=R \dot{I}
$$

Para obter a tensão $\dot{V}$ é necessário calcular a corrente elétrica do circuito, e para isso tem-se:

$$
\dot{\hat{V}}=\left(\begin{array}{c}
1 \\
j \omega C
\end{array}+R\right) \dot{I}
$$

na qual $C$ é a capacitância do transdutor, $j$ a parte imaginária e $\omega$ é igual a $2 \pi f$, onde $f$ é a freqüência. 
Desenvolvendo a equação 1.5, obtem-se:

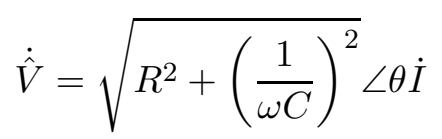

Sendo

$$
\theta=\arctan \begin{gathered}
1 \\
\omega R C
\end{gathered}
$$

o ângulo de defasagem entre a corrente e a tensão elétrica, dado pela impedância do circuito.

$$
\dot{\hat{V}}=\frac{\sqrt{ }(R \omega C)^{2}+1}{\omega C} \operatorname{Li}
$$

Isolando a corrente elétrica $\dot{I}$ :

$$
\dot{I}=\frac{\dot{\hat{V}} \omega C}{\sqrt{ }(R \omega C)^{2}+1} \angle-\theta
$$

Portanto:

$$
\dot{V}=R\left(\begin{array}{c}
\dot{\hat{V}} \omega C \\
\sqrt{ }(R \omega C)^{2}+1
\end{array}<-\theta\right)
$$

E pela equação 1.3, temos:

$$
\dot{V}=\begin{array}{cc}
S \hat{S} \sigma_{1} \\
\epsilon_{0}\left(S+\epsilon S_{1}\right)
\end{array} \cdot \underset{R \omega C}{\sqrt{ }(R \omega C)^{2}+1} L-\theta
$$

Para $R$ muito grande, o ângulo $\theta$ tende a zero e não existirá nenhuma defasagem entre a oscilação mecânica e a tensão de saída $V$.

Embora a teoria dos microfones de eletretos possa ser empregada na explicação dos novos eletretos termo-formados, aperfeiçoamentos teóricos estão sendo realizadas pelo Mestre Cláudio Vara de Aquino em seu trabalho de doutorado dentro do grupo de pesquisa sob a orientação do prof. Heitor C. Basso. Neste trabalho serão considerados espaçamentos de ar maiores e o amortecimento mecânico da amostra. 


\subsection{Aplicações}

O descobrimento do efeito piezoelétrico nos polímeros ampliou as áreas de aplicações, para o desenvolvimento de novos transdutores, atuadores, sensores de pressão, sensores acústicos e etc. Atualmente esses materiais podem ser encontrados em sistemas de monitoramento de paciente em hospitais (EMFIT, 2006), em teclados e painéis (Key Pads) (SCREENTEC, 2006) e inúmeros tipos de transdutores (B-BAND, 2006). A figura 1.13 mostra um exemplo de um teclado (Key Pads) desenvolvido com filmes piezoelétricos de polímeros.

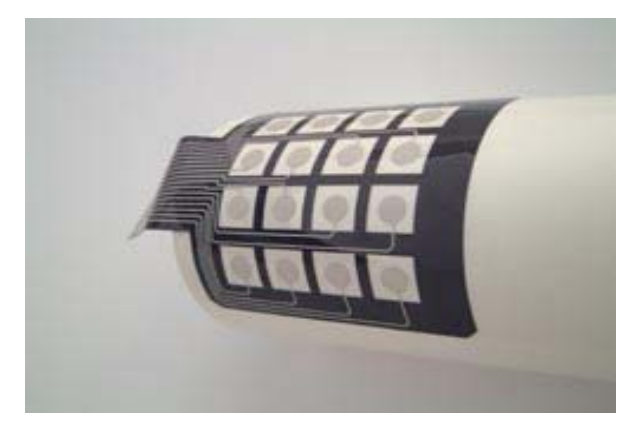

Figura 1.13: Teclado a base de filme polimérico (SCREENTEC, 2006).

Os novos polímeros também permitiram o desenvolvimento de dispositivos capazes de gerar sua própria energia, sem a necessidade de recarga ou troca de bateria. (GOEL, 2003). Embora esta seja uma área ainda pouco explorada, uma nova linha de pesquisa tem atraído mais a atenção dos pesquisadores, que é a utilização dos polímeros piezoelétricos no desenvolvimento da tecnologia dos sistemas micro-eletro-mecânicos (MEMS).

Os MEMS são sistemas compostos por elementos mecânicos, sensores, atuadores e elementos eletrônicos construídos com tecnologia de microeletrônica sobre uma base de silício (MEMS \& CLEARINGHOUSE, 2001). Com essa tecnologia, que objetiva desenvolver micro-máquinas capazes de realizar funções mecânicas, ópticas e biológicas, foi possível construir recentemente, microfones de eletretos extremamente reduzidos utilizando filmes de Teflon-AF ou de PVDF (GOEL, 2003).

Apesar das inúmeras aplicações para os materiais piezoelétricos, o objetivo deste trabalho é desenvolver processos de medidas, podendo assim caracterizar os trans- 
dutores de pressão desenvolvidos no laboratório de Medidas e Padrões da Escola de Engenharia Elétrica da Universidade de São Paulo - São Carlos. 


\section{Capítulo 2}

\section{Principais Métodos de Medida da Piezoeletricidade}

Considerando que diferentes métodos de medidas do efeito piezoelétrico já foram projetados para caracterizar os materiais piezoelétricos, este capítulo objetiva descrever e analisar de forma crítica os métodos que melhor se adaptam na caracterização dos eletretos termo-formados.

\subsection{Medida da piezoeletricidade em biopolímeros}

Na década de 50 a piezoeletricidade nos cristais e cerâmicas já estava sedimentada, inclusive com sistemas de medidas padronizados (ANSI, 1987). No entanto para demonstrar que a propriedade piezoelétrica também poderia ser encontrada nos biopolímeros, Fukada substituiu o cristal piezoelétrico em contato com a agulha de um gramofone, por uma pequena placa retangular com fibras de um colágeno (biopolímero) devidamente orientadas. Com isso ele obteve uma pequena resposta elétrica através da compressão e descompressão dessa placa (FUKADA, 2000).

No início dos anos setenta, significativas pesquisas com polímeros ocorreram, quando Hayakawa, Wada, Lewiner e colaboradores mostraram que polímeros polarizados também exibiam o efeito piezoelétrico (HAYAKAWA \& WADA, 1971); (HAYAKAWA \& WADA, 1973); (HAYAKAWA \& WADA, 1976); (DREYFUS \& LEWINER, 1973). Embora os coeficientes piezoeletricos encontrados nessa época eram muito bai- 
xos, para merecerem atenção nas aplicações de engenharia.

Essa situação mudou nos anos 80, quando foram desenvolvidos os polímeros porosos e celulares, que quando polarizados apresentavam coeficientes piezoelétricos superiores a 800 pC/N (KIRJAVAINEN, 1987); (SAVOLAINEN \& KIRJAVAINEN, 1989); (GERHARD-MULTHAUPT et al., 1999).

Com a evolução dos eletretos, novos métodos de medidas foram desenvolvidos para caracterizar esses materiais. Neste contexto, foi realizado uma análise com as vantagens e desvantagens de alguns métodos que normalmente são empregados na caracterização dos polímeros piezoelétricos, para possível implementação e caracterização dos eletretos termo-formados.

\subsection{Métodos de medida da piezoeletricidade}

Os métodos de medida da piezoeletricidade podem ser divididos em dois grupos: os métodos diretos e os métodos inversos. Os métodos de medida diretos, são todos aqueles que aplicam uma pressão mecânica sobre o material e analisam a resposta elétrica. Os métodos de medida inversos, são aqueles que excitam o material eletricamente e analisam a resposta mecânica.

\subsubsection{Método direto de medida da piezoeletricidade}

Os métodos diretos de medida da piezoeletricidade ainda podem ser classificados em quase-estáticos e dinâmicos, dependendo da freqüência com que a pressão externa é aplicada.

\section{Método quase-estático de medida da piezoeletricidade}

O método de medida quase-estático é empregado de forma qualitativa apenas para comprovar a existência do efeito piezoelétrico em um determinado material. Este método, consiste em aplicar uma força, geralmente causada por um corpo de massa $m$, sobre uma área definida da amostra e coletar o sinal elétrico de resposta através de um osciloscópio (HILLENBRAND \& SESSLER, 2004b). Uma das formas de implementar esse método é apresentado na figura 2.1. 


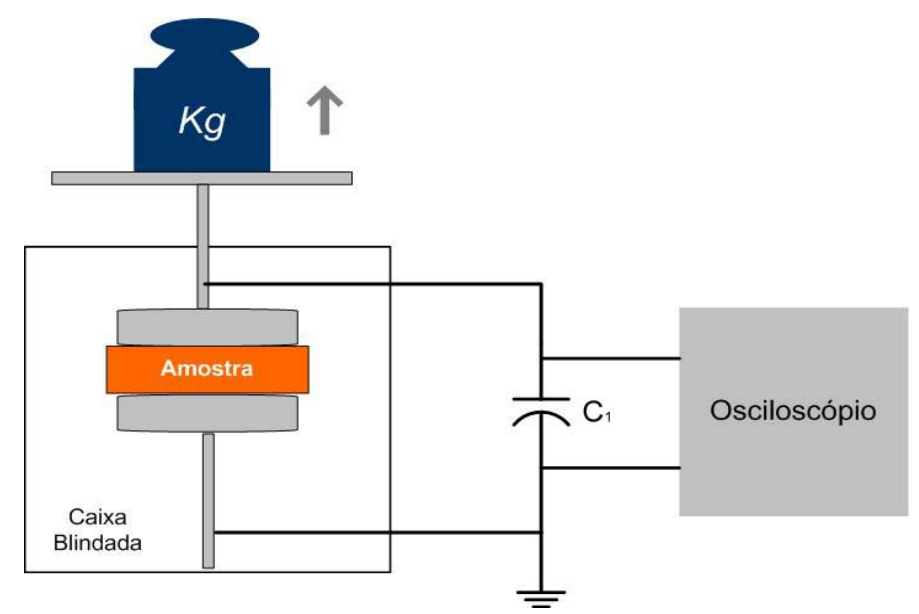

Figura 2.1: Modelo esquemático do processo quase-estático.

Neste método uma amostra polarizada é posicionada entre dois eletrodos devidamente polidos e conectados a um capacitor em paralelo $C_{1}$, com uma capacitância pelo menos 100 vezes maior que a capacitância da amostra. O fato da amostra estar polarizada, produz cargas elétricas induzidas na superfície dos eletrodos que permanecem em equilíbrio até que a amostra seja submetida a uma variação de pressão. Como o capacitor C está em paralelo e possui uma capacitância muito maior que da amostra, ao variar a pressão na amostra as cargas elétricas são transferidas para ele (ALTAFIM et al., 2005).

Medindo-se a tensão elétrica no capacitor é possível obter o coeficiente piezoelétrico $d_{33}$, ou seja, a razão entre a carga elétrica $Q$ e a força aplicada, $F$ através da equação 2.1 .

$$
d_{33}={ }_{F}^{Q}=\begin{gathered}
C . V \\
F
\end{gathered}
$$

sendo $V$, a tensão elétrica e $C$ a capacitância do capacitor de medida. O coeficiente piezoelétrico é expresso em pico Coulomb por Newton $(p \mathrm{C} / \mathrm{N})$.

A variação da pressão é obtida retirando-se o corpo da amostra manualmente, o que provoca ruídos elétricos e interferência nas medidas. Para uniformizar a resposta deste método e diminuir os ruídos elétricos, foi desenvolvido um dispositivo eletromecânico utilizando-se um eletroímã para suspender o corpo, conforme a figura 2.2. Ao produzir uma descompressão uniforme sobre a amostra sem interferência direta, conseguiu-se diminuir os ruídos elétricos e as variações de resultados provocadas pela não uniformidade da descompressão (LIMA, 2005). 


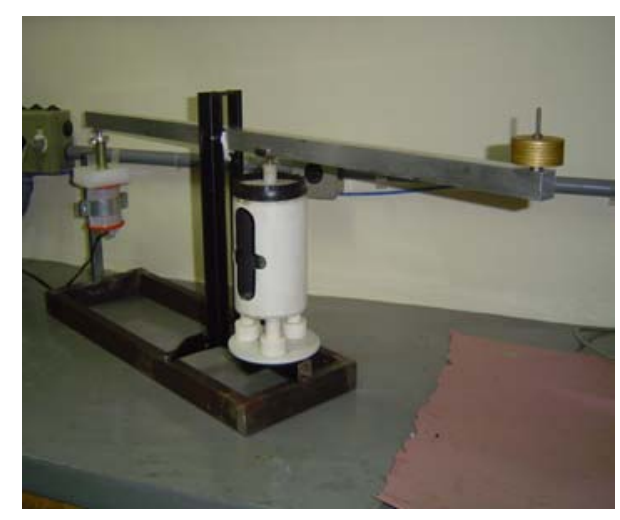

Figura 2.2: Equipamento para exercer uma descompressão mais uniforme na amostra (LIMA, 2005).

O método de medida quase-estático embora consiga mostrar resultados importantes relacionando pressão mecânica e sinal elétrico, não disponibiliza informações sobre a resposta em freqüência das amostras, o que torna o método incompleto para caracterizar os materiais piezoelétricos, uma vez que inúmeras aplicações exigem o conhecimento da resposta em freqüência.

Para completar o método quase-estático e suprir a falta de informação sobre o comportamento do material em relação a freqüência, foram desenvolvidos métodos dinâmicos de medida do coeficiente piezoelétrico.

\section{Método dinâmico de medida da piezoeletricidade}

O método dinâmico direto de medida do coeficiente piezoelétrico pode ser compreendido como uma extensão do método quase-estático, uma vez que neste processo a pressão quase-estática é substituída por um mecanismo controlado de pressão capaz de aplicar uma mesma força em diferentes freqüências.

Uma das formas de se implementar este método pode ser visto na figura 2.3, na qual utiliza-se um shaker (dispositivo mecânico de vibração) e um corpo de massa $m$. Ao vibrar o shaker provoca uma aceleração na amostra, que passa a sofrer a ação de duas forças, a força estática $m g$ e a força dinâmica $m a$, onde $g$ é a aceleração da gravidade e $a$ é a aceleração dinâmica causada pelo shaker.

A aceleração dinâmica medida através de um acelerômetro, permite deter- 
minar a força que o corpo exerce sobre a amostra. Através da soma das forças e da resposta do sinal elétrico pode-se obter o coeficiente piezoelétrico (HILLENBRAND \& SESSLER, 2004b).

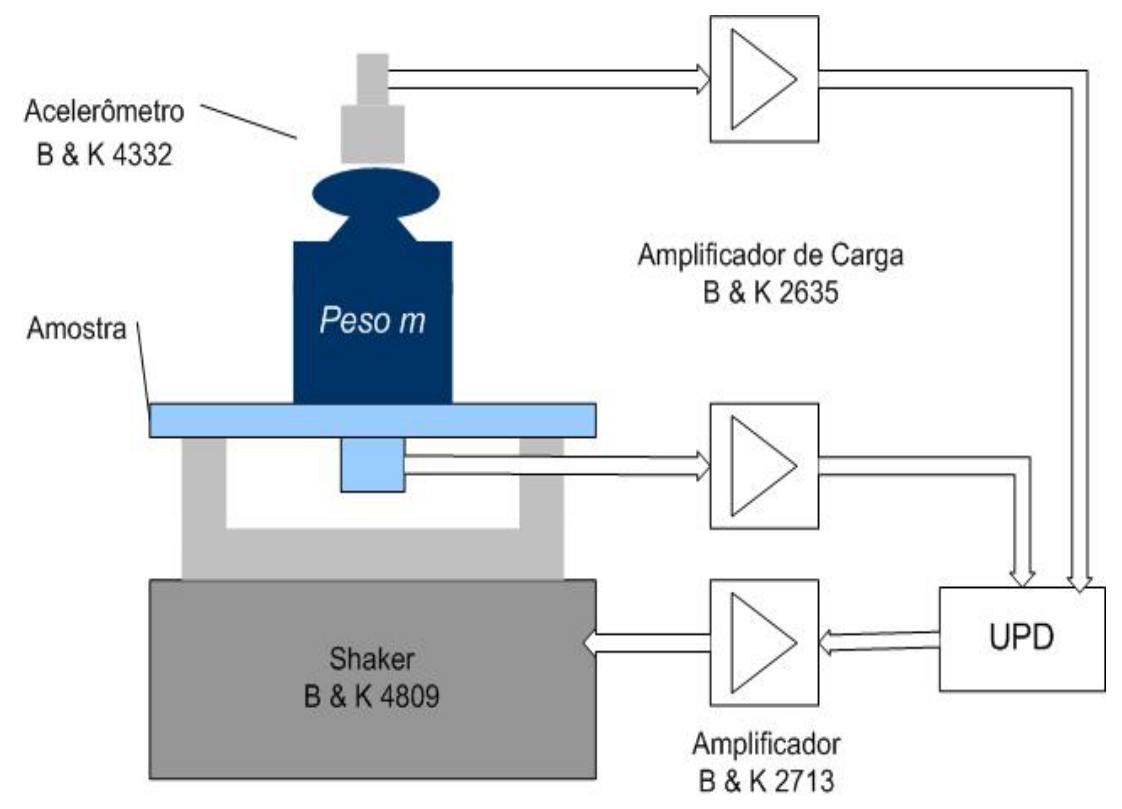

Figura 2.3: Sistema de medida dinâmico com shaker (HILLENBRAND \& SESSLER, 2004b).

A implementação deste método conforme a figura 2.3, permite uma flexibilidade maior na realização das medidas, pois além da freqüência pode-se também alterar o corpo sobre a amostra, tornando esse método muito vantajoso para caracterizar amostras de filmes poliméricos.

No entanto, esse sistema possui um custo de implementação que chega a atingir dezenas de milhares de dólares apenas para o sistema de aquisição de dados. Outro problema que está relacionado com esse sistema é a provável destruição das amostras devido ao atrito do corpo com a amostra. Essa deterioração das amostras impede que novas medidas sejam realizadas, impossibilitando medidas comparativas.

Para realizar as medidas dinâmicas diretas a um custo mais acessível foi desenvolvido um sistema utilizando controle de pressão pneumática para realizar a varredura em freqüência conforme visto na figura 2.4 (KIM \& KIM, 1998). 


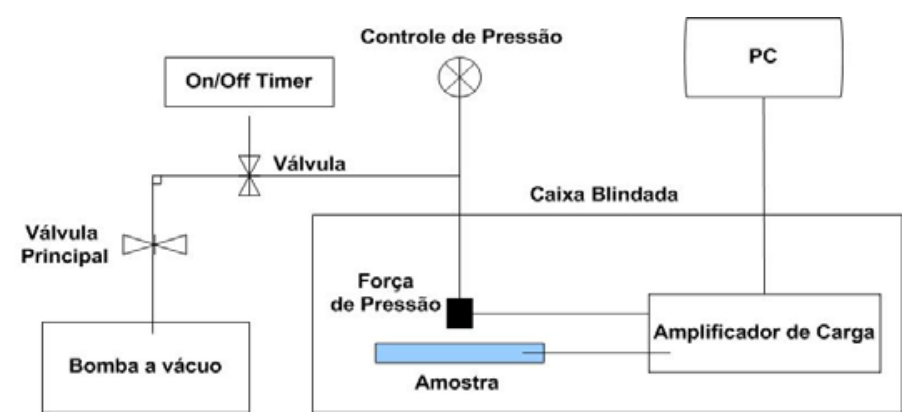

Figura 2.4: Sistema de medida dinâmico utilizando pressão pneumática (KIM \& KIM, 1998).

Neste sistema a bomba a vácuo com o auxílio de válvulas, diminui a pressão sobre a amostra e o temporizador (Timer), controla a freqüência com que a pressão é aplicada. Embora este método apresente uma construção mais complexa que o sistema anterior e não permita uma grande varredura em freqüência, ele garante uma redução nos custos com aquisição de dados, que é realizada através de um computador (PC) e um amplificador de sinal.

Apesar dos métodos dinâmicos diretos de medidas suprirem as necessidades de medida do coeficiente piezoelétrico dinamicamente, eles ainda apresentam os problemas de destruir ou de danificar as amostras e limitação de resposta em freqüência, em torno de $10 \mathrm{kHz}$.

\section{Método acústico direto de medida da piezoeletricidade}

Uma forma encontrada para realizar a caracterização dinâmica sem causar danos nas amostras é através do método de medida acústico direto, no qual um altofalante proporciona uma pressão acústica sobre a amostra. As ondas sonoras criadas pelo alto-falante atuam como uma força externa de baixa intensidade, fazendo com que a amostra responda com um sinal elétrico (KRESSMANN, 2001).

O método acústico direto pode ser implementado seguindo a descrição dada por (KRESSMANN, 2001), na qual utiliza-se os seguintes equipamentos: uma gaiola cilíndrica de calibrar microfones, um auto-falante capaz de produzir pressões entre 20 $\mathrm{mPa}$ e $340 \mathrm{~Pa}$, sem a necessidade de adição de carga estática, e um microfone para medir a intensidade da pressão gerada pelo auto-falante. A forma como esse sistema 
pode ser montado, é observado na representação esquemática da figura 2.5.

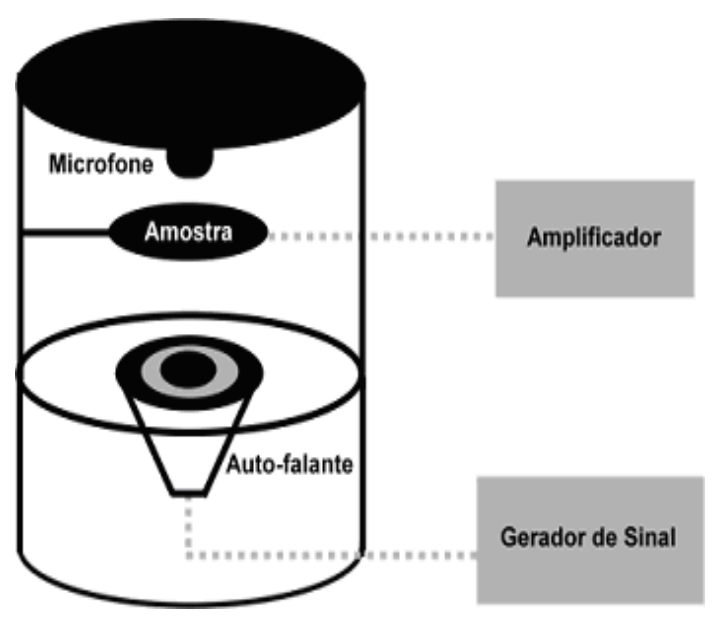

Figura 2.5: Representação esquemática do sistema acústico direto.

Este método permite percorrer uma grande faixa de freqüência, limitando-se apenas pela resposta do alto-falante, e não danifica a amostra. O que permite realizar um estudo da variação das cargas elétricas em função do tempo.

No entanto, as medidas de baixas, médias e altas freqüências devem ser feitas em etapas separadas, pois nenhum alto-falante é capaz de abranger todas essas freqüências sem distorções.

\subsubsection{Métodos inversos de medida da piezoeletricidade}

Como o efeito piezoelétrico manifesta-se de forma direta e inversa, a caracterização dos materiais piezoelétricos pode ser realizada através do estímulo elétrico e análise de seu comportamento mecânico. Esses métodos de caracterização, são apresentadas como métodos de medida inversos e o coeficiente inverso é medido em pico metro por Volt (pm/V), ou seja deformação por tensão aplicada.

\section{Método acústico inverso de medida da piezoeletricidade}

O sistema acústico inverso de medida da piezoeletricidade é baseado na medição da pressão sonora gerada pelos materiais piezoelétricos, quando uma tensão elétrica é aplicada nos eletrodos da amostra. O estímulo elétrico provoca uma deformação mecânica capaz de produzir sons que variam conforme a freqüência do sinal 
elétrico aplicado. Com o auxílio de um microfone de precisão é possível medir a intensidade desses sons (WEINHOLD et al., 2000). Uma montagem desse sistema pode ser vista na figura 2.6 .

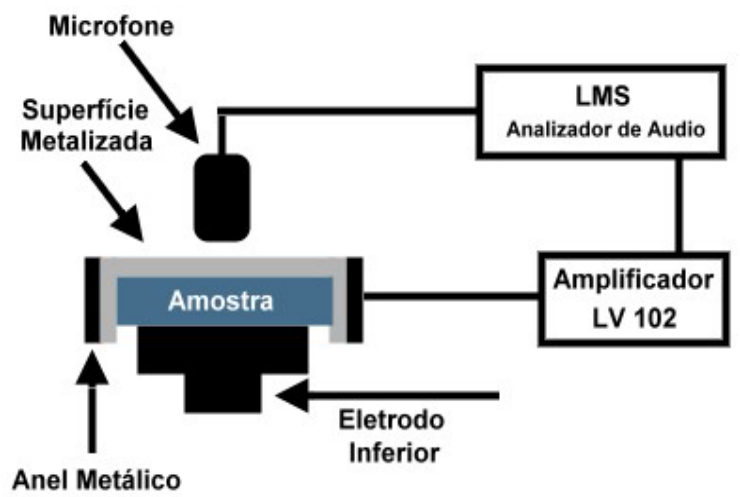

Figura 2.6: Sistema de medida dinâmico acústico inverso (WEINHOLD et al., 2000).

O método acústico inverso garante resultados satisfatórios na caracterização de materiais piezoelétricos e define claramente o comportamento da amostra. No entanto, este método quando aplicado aos eletretos termo-formados não permite distinguir se o comportamento observado é relativo as bolhas ou do próprio filme, visto que o filme de Teflon-FEP esticado e excitado eletricamente também produz sons. Este método também, requer várias considerações e cálculos matemáticos complexos para converter a intensidade sonora em deslocamento.

\section{Método de medida do coeficiente piezoelétrico com acelerômetro}

O Método de medida do coeficiente piezoelétrico com acelerômetro, requer apenas um amplificador de carga e um acelerômetro, como mostra a figura 2.7. Para obter o coeficiente piezoelétrico através desse método, deve-se calcular o deslocamento da amostra através da medida da aceleração da amostra, obtida com um acelerômetro.

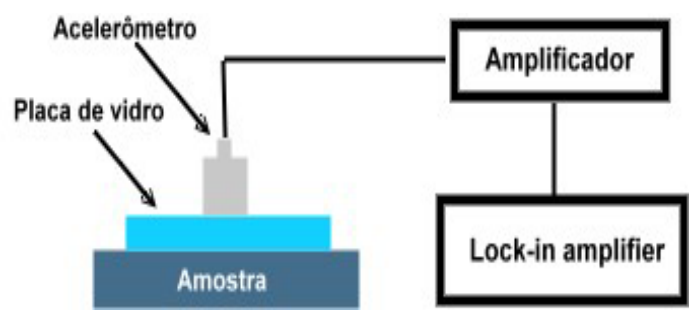

Figura 2.7: Sistema de medida dinâmico com acelerômetro. 
Algumas medidas do coeficiente piezoelétrico inverso foram feitas com este método por (HILLENBRAND \& SESSLER, 2000) para uma faixa de freqüência de até $10 \mathrm{kHz}$, utilizando-se um acelerômetro, uma placa de vidro de $1 \mathrm{~mm}$ de espessura e 25 $\mathrm{cm}^{2}$ de área e um amplificador de carga (Brüel \& Kjaer 2635) na entrada de um lock-in (EG\&G Instruments 5110), conforme o esquema da figura 2.7.

Nessa caracterização feita por (HILLENBRAND \& SESSLER, 2000) a amostra foi excitada com uma tensão elétrica senoidal de $V_{m r s}<100 \mathrm{~V}$ provocando um pequeno deslocamento na superfície da placa de vidro. Essa variação foi calculada matematicamente através da aceleração $a$ captada pelo acelerômetro e das equações 2.2 e 2.3 , resultando no coeficiente piezoelétrico $d_{33} \mathrm{em} \mathrm{pm} / \mathrm{V}$.

$$
\begin{gathered}
d_{33}=\begin{array}{l}
S \\
V
\end{array} \\
S=S_{0}+v_{0} T+a T^{2} / 2
\end{gathered}
$$

Nas quais $S$ é o deslocamento, $V$ a tensão elétrica aplicada, $T$ o tempo obtido pela freqüência, $S_{0}$ o deslocamento inicial e $v_{0}$ a velocidade inicial, que para este caso $S_{0}$ e $v_{o}$ são iguais a 0.

No entanto, ao colocar uma placa de vidro sobre a amostra para ampliar a superfície de contato entre o acelerômetro e a amostra, ocorreu uma alteração nas características da amostra, pois o peso do vidro e do acelerômetro exercem uma pressão inicial sobre a amostra. Essa pressão provavelmente produz uma compressão das bolhas, descaracterizando as medidas (HILLENBRAND \& SESSLER, 2000).

\section{Método de medida do coeficiente piezoelétrico por interferometria}

O método por interferometria permite medir a deformação da amostra causada pelo sinal elétrico, sem nenhuma interferência mecânica, através da medição das ondas de interferência criadas pela luz. A figura 2.8 mostra uma representação esquemática de um interferômetro de Michelson que geralmente é utilizado na caracterização dos materiais piezoelétricos. 


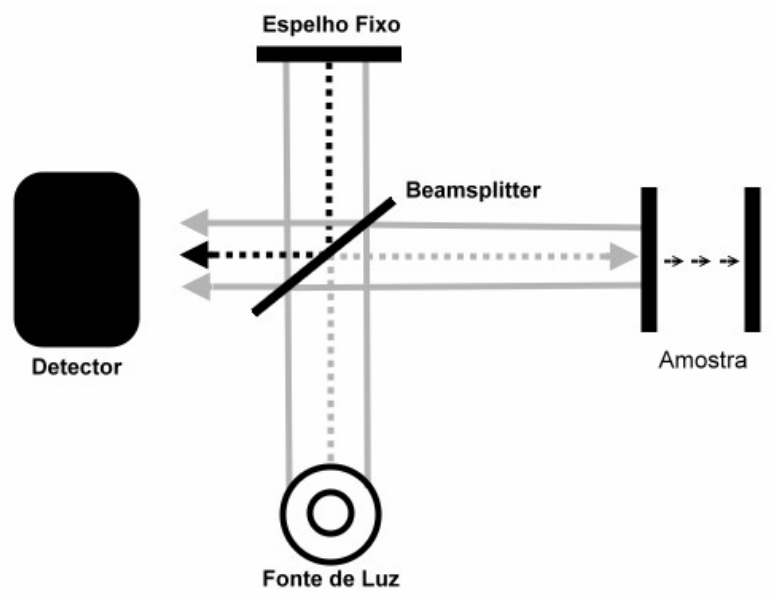

Figura 2.8: Interferômetro de Michelson.

Neste método a reflexão da luz produz ondas de interferências que se movimentam conforme a vibração do espelho móvel. Ao substituir o espelho móvel por uma amostra e excitar a amostra eletricamente, é possível detectar o deslocamento da amostra através das ondas de interferência criadas pela reflexão da luz. Esse movimento pode ser detectado através de um fotodetector e com o valor deslocamento da amostra em função da tensão aplicada, obtém-se o coeficiente piezoelétrico (pm/V).

A figura 2.9 mostra as ondas de interferência criadas em um interferômetro.

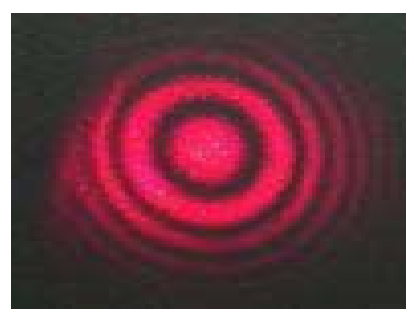

Figura 2.9: Ondas de interferência criadas pelo interferômetro.

Este sistema permite realizar medidas para faixas de freqüências de $1 \mathrm{~Hz}$ até $400 \mathrm{kHz}$ sem danificar as amostras, simplesmente substituindo o espelho móvel por amostras devidamente metalizadas. No entanto o custo de implementação deste método é relativamente alto, devido a necessidade de equipamentos de óptica de precisão e obter amostras com superfícies refletoras o suficiente para provocar as ondas de interferência, requer amostras com superfícies planas e metalizações precisas.

Algumas soluções alternativas podem ser encontradas na literatura para o 
procedimento interferométrico. Como é o caso do sistema apresentado na figura 2.10 (FUKADA, 2000), que consiste em um eletrodo anelado fixado em uma base isolante, coberto por uma fina camada de um líquido dielétrico, e um leve e fino espelho flutuante sobre o líquido.

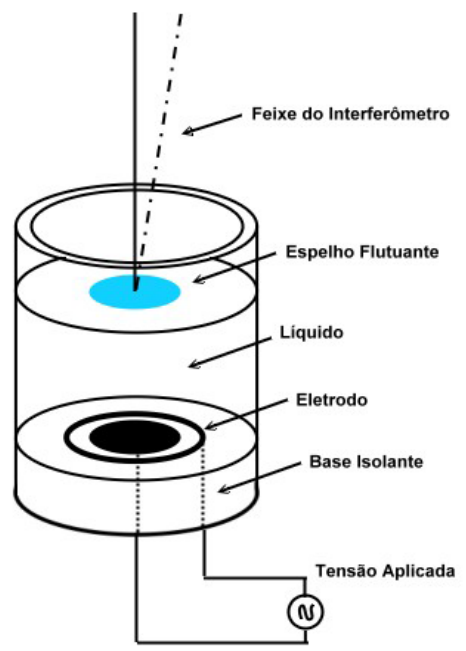

Figura 2.10: Montagem experimental utilizando um interferômetro (FUKADA, 2000).

Neste método, ao aplicar uma tensão na amostra presa ao eletrodo, é possível observar um movimento circular do espelho, causado pela propagação da onda gerada pela vibração da amostra. Essa vibração pode ser medida no interferômetro.

Esta alternativa embora funcione adequadamente, gera novos problemas como o do peso do líquido sobre a amostra, que influenciam diretamente as medidas. Isso torna o método inviável no processo de caracterização das amostras com múltiplas bolhas de Teflon-FEP.

Após a análise dos principais métodos utilizados na caracterização dos polímeros piezoelétricos, foram escolhidos quatro métodos para a caracterização dos eletretos termo-formados. Estes métodos serão apresentados no capítulo seguinte com maiores detalhes. 


\section{Capítulo 3}

\section{Caracterização dos eletretos termo-formados}

Os eletretos termo-formados desenvolvidos pelo laboratório de Medidas e Padrões da Escola de Engenharia Elétrica - USP -São Carlos, foram desenvolvidos embasados em conceitos físicos consolidados, a exemplo a teoria do microfone de eletreto, mas com uma nova perspectiva. Essa mudança de paradigma exigiu uma nova compreensão dos métodos de caracterização estáticos e dinâmicos. E apesar de ter sido feita uma caracterização quase-estática sobre os moldes dos métodos existentes (LIMA, 2005), a caracterização dinâmica ainda não foi realizada nesses eletretos.

Com o intuito de caracterizar dinamicamente os eletretos termo-formados, no capítulo anterior, foi realizada uma análise com diversos métodos de caracterização dinâmica. Essa análise permitiu encontrar quatro métodos exeqüíveis com as disponibilidades laboratoriais e com as características dos eletretos termo-formados. Esses métodos são: o método dinâmico direto, o óptico e os métodos acústicos, direto e inverso.

Na implementação destes métodos, algumas soluções e substituições foram propostas e encontram-se descritas nos itens subseqüentes deste capítulo. 


\subsection{Sistema mecânico direto}

O primeiro método de caracterização dinâmico implementado foi o método dinâmico direto de (HILLENBRAND \& SESSLER, 2004b). Nele, um dispositivo de vibração (shaker) acelera uma amostra do material piezoelétrico contra um peso de massa $m$. A resultante da força estática $m g$ e da força dinâmica $m a$, onde $g$ é a aceleração da gravidade e $a$, a aceleração dinâmica aliada a resposta elétrica possibilita determinar o coeficiente piezoelétrico.

Embora este seja um método de fácil compreensão, ele requer equipamentos específicos, de alta precisão e de alto custo. Na busca de uma solução econômica, foi proposto um novo sistema dinâmico. Nesse sistema, o shaker foi substituído por um alto-falante de baixa freqüência e o acelerômetro, por um anteparo metálico fixo, contra o qual a amostra é pressionada. Desta forma, ao invés de usar a aceleração para calcular a força que o peso exerce na amostra, mede-se força que o alto-falante exerce na amostra.

Nas figuras 3.1 e 3.2 pode ser visualizado o novo sistema implementado. Montada sobre uma estrutura metálica, uma cuba de alumínio aterrada fornece o suporte para o eletrodo circular superior e garante uma blindagem elétrica eficiente. Abaixo dessa cuba encontra-se um alto-falante, com um eletrodo inferior preso ao seu cone. $\mathrm{Na}$ configuração estática, esse eletrodo fica levemente pressionado sobre o eletrodo superior.

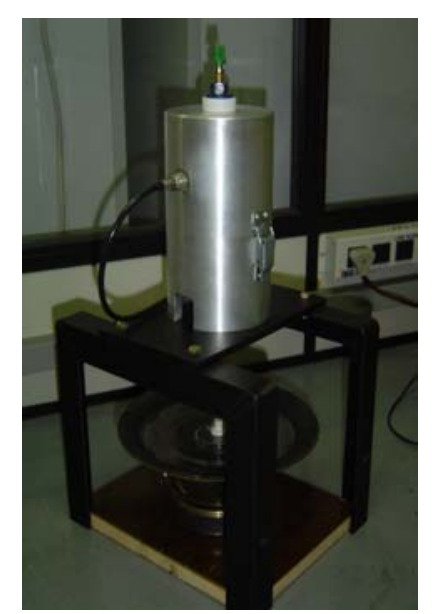

Figura 3.1: Método de medida por vibração mecânica.

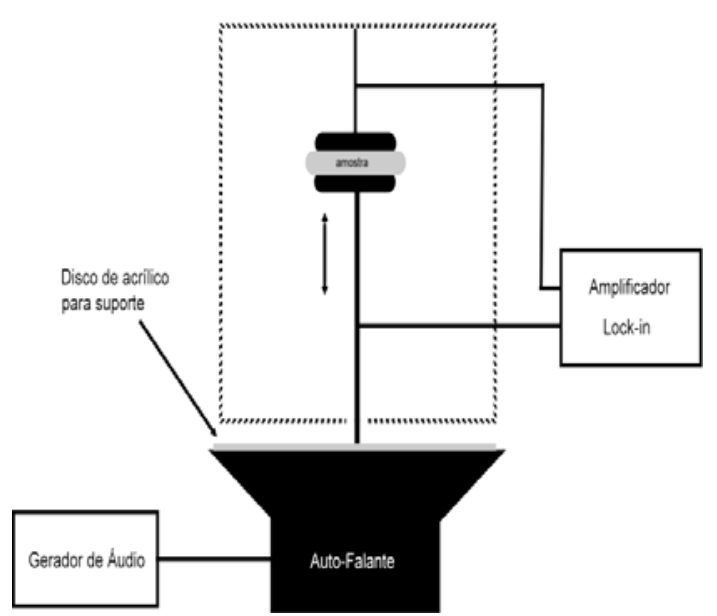

Figura 3.2: Representação esquemática do sistema.

Ao excitar-se o alto-falante por um sinal elétrico senoidal, um movimento 
oscilatório vertical é gerado. Uma amostra piezoelétrica posicionada entre esses dois eletrodos fica periodicamente pressionada gerando como resposta um sinal elétrico.

O alto-falante como gerador de pressão apresentou alguns problemas, dentre eles a alteração da força com a freqüência, que deveria ser constante. Também o ruído sonoro produzido pelo alto-falante interfere em todo o processo de caracterização.

O problema relativo à variação da intensidade da força foi solucionado, calibrando-se o sistema. Nesta calibração, aplicou-se uma tensão de corrente contínua (DC) no alto-falante com uma fonte Tektronix, modelo CPS250, mediu-se a corrente elétrica com um multímetro (Minipa ET-2700) em um resistor de 1,14 $\Omega$ ligado em série e a força exercida pelo alto-falante com um dinamômetro (FG $5000^{\mathrm{a}}$ ). Os resultados encontram-se apresentados na tabela 3.1.

Tabela 3.1: Resultado da calibração do sistema.

$\begin{array}{rr}\text { Corrente }(\mathrm{A}) & \text { Força }(\mathrm{N}) \\ 0,3847 & 1,31 \\ 0,3693 & 1,22 \\ 0,3308 & 1,07 \\ 0,2847 & 0,86 \\ 0,2770 & 0,81 \\ 0,2231 & 0,61 \\ 0,1692 & 0,42 \\ 0,1000 & 0,18 \\ 0,0769 & 0,11\end{array}$

Com esses dados, foi possível plotar um gráfico no qual foi feito uma análise denominada linear fit. Através dessa análise, foi observado que existe uma correlação linear entre a força e a corrente elétrica definida pela equação 3.1. A figura 3.3 ilustrada o gráfico com a análise linear fit.

$$
F=-0,226+3,908 I
$$

na qual, $F$ é a força e $I$ é a corrente elétrica.

Apesar do sistema ser linear para tensões DC, não se pode garantir o mesmo comportamento para uma excitação senoidal. Assim, o sistema foi aferido também para tensões AC empregando-se um gerador de função Tektronix modelo CFG253 no lugar da fonte DC. 


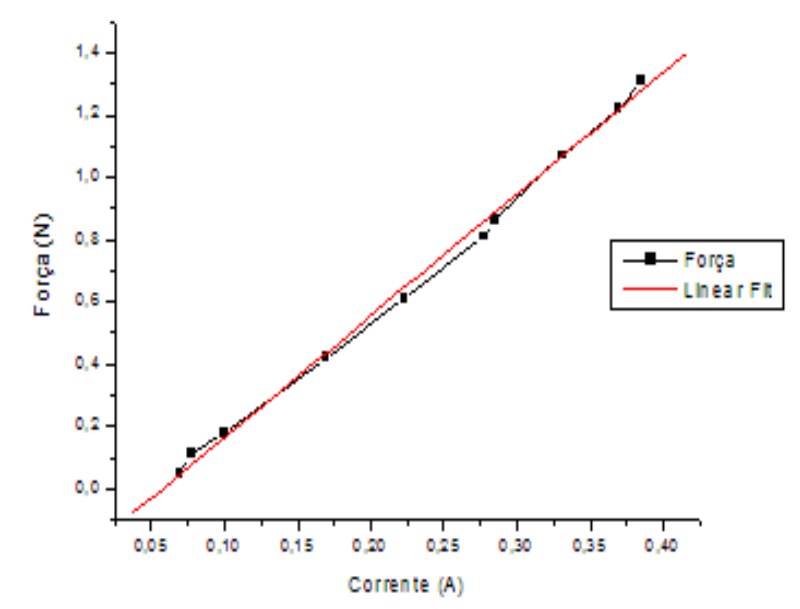

Figura 3.3: Relação entre a força exercida pelo alto-falante e a corrente elétrica.

Nesta calibração, variou-se a freqüência do sinal aplicado no alto-falante, mantendo-se a amplitude do sinal constante. Os valores da forças e das correntes encontram-se na tabela 3.2. Deles pôde-se extrair valor médio da força exercida pelo alto-falante, ou seja, igual à 1,14 N.

Tabela 3.2: Resultados obtidos na calibragem dinâmica.

$\begin{array}{rrr}\text { Freqüência }(\mathrm{Hz}) & \text { Corrente }(\mathrm{A}) & \text { Força }(\mathrm{N}) \\ 78 & 0,358 & 1,2409 \\ 206 & 0,352 & 1,2201 \\ 380 & 0,348 & 1,2062 \\ 1000 & 0,326 & 1,1299 \\ 1280 & 0,321 & 1,1147 \\ 1500 & 0,314 & 1,0897 \\ 2000 & 0,301 & 1,0454 \\ 2500 & 0,292 & 1,0149\end{array}$

Tendo-se calibrado o sistema e desprezado os ruídos sonoros, o sinal da amostra foi captado por um amplificador Lock-in da Stanford Research modelo SR510. As medidas iniciais foram feitas, varrendo-se as freqüências manualmente no gerador de função e anotando os dados obtidos no Lock-in. Esse procedimento além demorado, não permitia que as medidas fossem refeitas com os mesmos intervalos de tempo, comprometendo os resultados comparativos.

Para padronizar a varredura em freqüência e a coleta de dados, foi desenvol- 
vido um programa computacional para controle e aquisição dos dados. Esse programa denominado Sistema de Aquisição Lock-in SR510, é capaz de controlar o Lock-in e o gerador de função, tornando o processo de medidas automatizado.

O desenvolvimento deste software, também contribuiu para uma redução no tempo de aquisição de dados, que antes era feito manualmente e demorava horas. O funcionamento e as especificações deste software serão apresentadas no capítulo 4 .

As medidas realizadas após automatização do processo, apresentaram várias ressonâncias. Essas ressonâncias podem ter ocultado a verdadeira resposta das amostras, mas mostraram a dependência do sinal de resposta com a freqüência como se observa na figura 3.4. Esse comportamento também foi observado por (ZHANG et al., 2006) posteriormente, com estruturas semelhantes aos eletretos termo-formados.

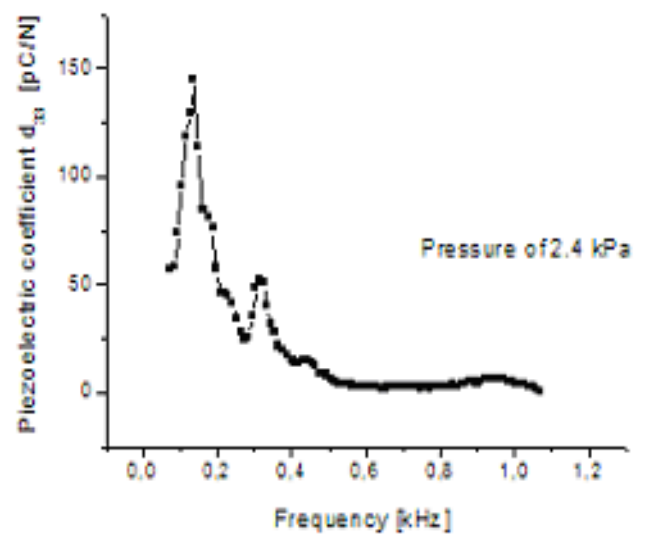

Figura 3.4: Resultados obtidos com o sistema automatizado (ALTAFIM et al., 2005).

Para tentar diminuir ou mesmo eliminar essas ressonâncias do sistema, a haste do eletrodo superior foi rebaixada de forma a exercer uma pressão constante sobre o alto-falante, evitando-o de oscilar mecanicamente. Entretanto, esse procedimento não impediu que uma pressão periódica fosse exercida sobre a amostra.

Mesmo com as modificações introduzidas, o sistema continuou a apresentar medidas com ressonâncias, fortemente correlacionadas com a flexão da haste muito fina. A solução encontrada foi acoplar o alto-falante a um tubo de Policloreto de Vinila (PVC) de dimensões menores e maior diâmetro.

Embora essa alteração tenha tornado o sistema mais robusto, foi observado que o peso do tubo de PVC influenciava no comportamento do alto-falante, que pas- 
sou a não mais responder linearmente. Procurando sanar esse problema, inverteu-se verticalmente todo o conjunto para retirar o peso do tubo de PVC sobre a amostra. A figura 3.5 mostra a nova configuração do sistema após as modificações introduzidas.

Contudo, a calibração final deste sistema ainda não foi realizada e deve ser objeto de estudos futuros.

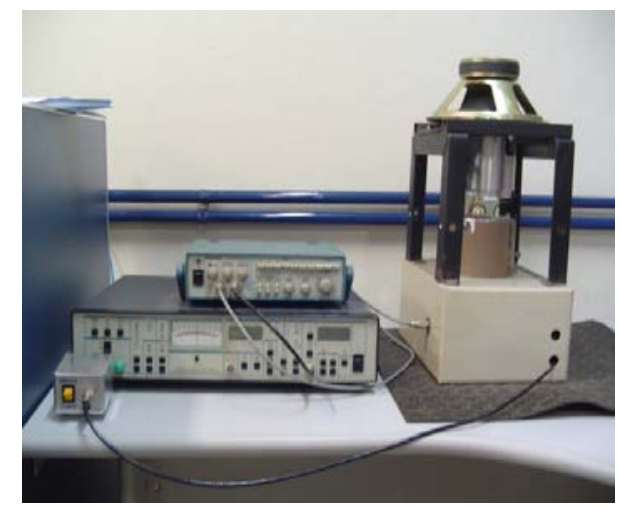

Figura 3.5: Sistema de medida dinâmico com o alto-falante invertido.

Medidas com esse novo sistema foram realizadas com amostras produzidas pelo processo de produção dos eletretos termo-formados desenvolvido por (LIMA, 2005). Mas como pode-se observar nas figuras 3.6 e 3.7 esse processo de produção de amostras produz amostras perfeitas e amostras com deformações estruturais, ou seja, com bolhas de diferentes tamanhos.

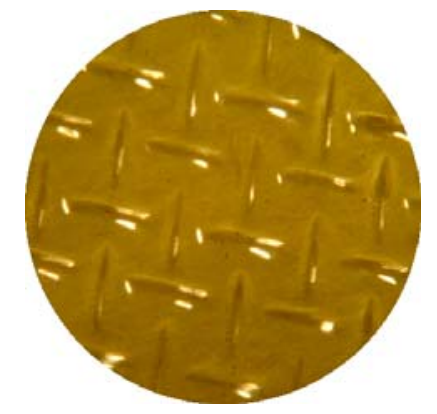

Figura 3.6: Amostra sem deformação estrutural.

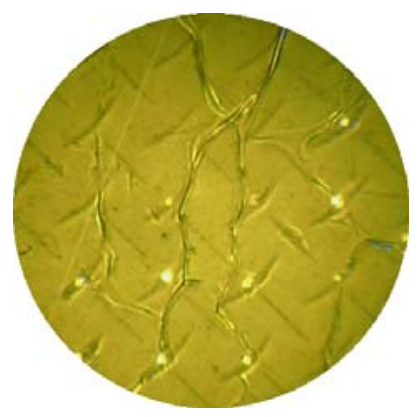

Figura 3.7: Amostra com deformação estrutural.

Essas irregularidades como se pode observar nos gráficos apresentados nas figuras 3.8, 3.9, 3.10 e 3.11 interferem diretamente nos resultados, dificultando carac- 
terizar o comportamento dinâmico dos eletretos termo-formados.

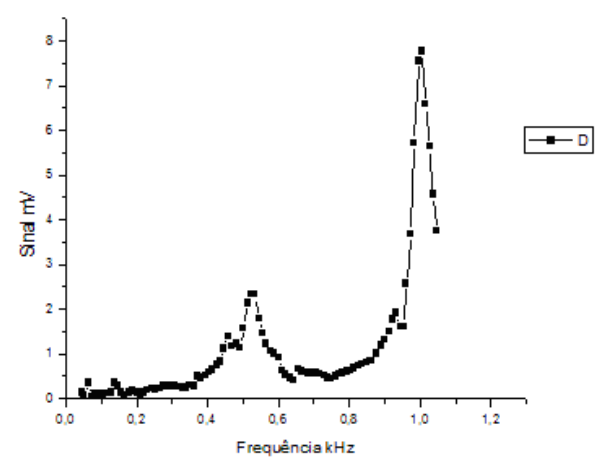

Figura 3.8: Amostra homogênea - $1^{\mathrm{O}}$ medida.

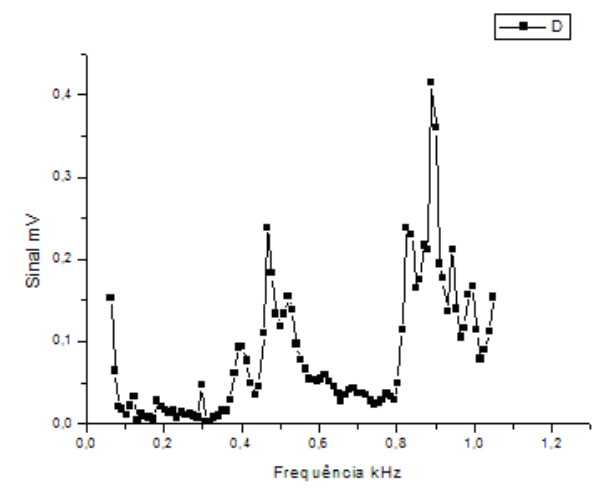

Figura 3.10: Amostra com falhas estruturais - $1^{\circ}$ medida.

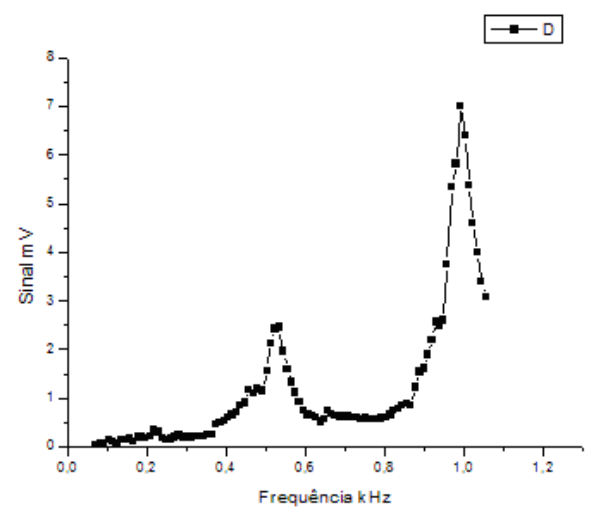

Figura 3.9: Amostra homogênea - $2^{\circ}$ medida.

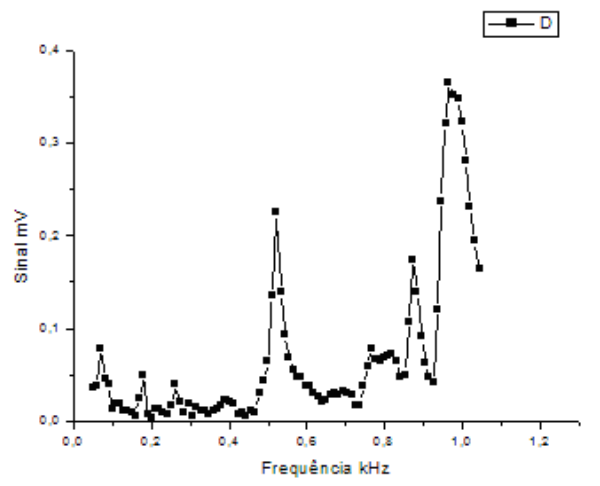

Figura 3.11: Amostra com falhas estruturais - $2^{\circ}$ medida..

Após separar e classificar as amostras em homogêneas e aquelas com defeitos estruturais, foi realizado um ensaio para observar a influência da polarização e na resposta da amostra. Este ensaio foi realizado com a amostra parcialmente descarregada, pois existem cargas eletrostáticas presas na amostra, e com a amostra carregada com uma tensão de $6 \mathrm{kV}$ pelo método impulsivo (ALTAFIM et al., 2003). Os resultados desse ensaio mostram um acréscimo no sinal de resposta dessa amostra de aproximadamente $17 \mathrm{mV}$, como se observa nos gráficos das figuras 3.12 e 3.13. O que comprova que o carregamento impulsivo, funciona para os eletretos termo-formados. 


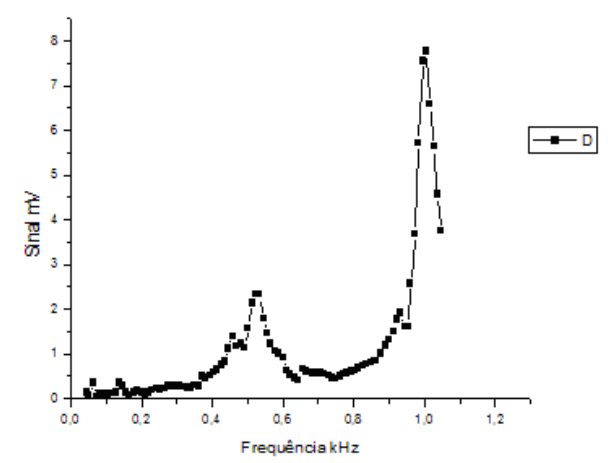

Figura 3.12: Amostra descarregada.

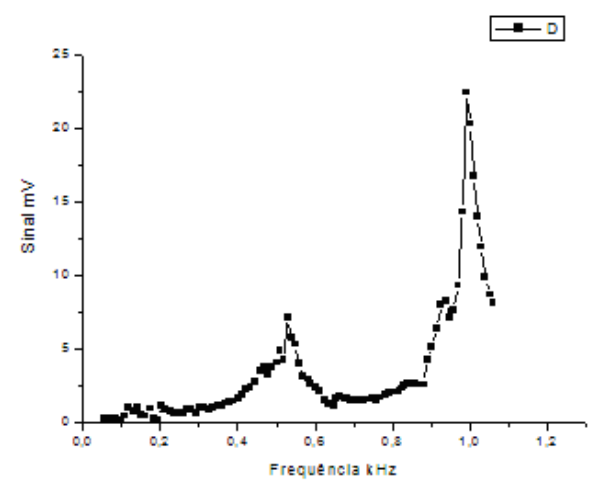

Figura 3.13: Amostra carregada.

Este método dinâmico, também foi utilizado para verificar uma possível perda de cargas elétricas das amostras, durante um determinado período de tempo. Nessas medidas uma amostra foi caracterizada após ser carregada e depois de um período de sete dias. Durante esse período a amostra permaneceu em repouso sem qualquer contato físico.

Os resultados dessas medições, encontram-se nos gráficos das figuras 3.14 e 3.15 respectivamente e comprovam que no período de uma semana, não houve qualquer indício de que a amostra pudesse estar perdendo cargas elétricas, já que seu comportamento não foi alterado.

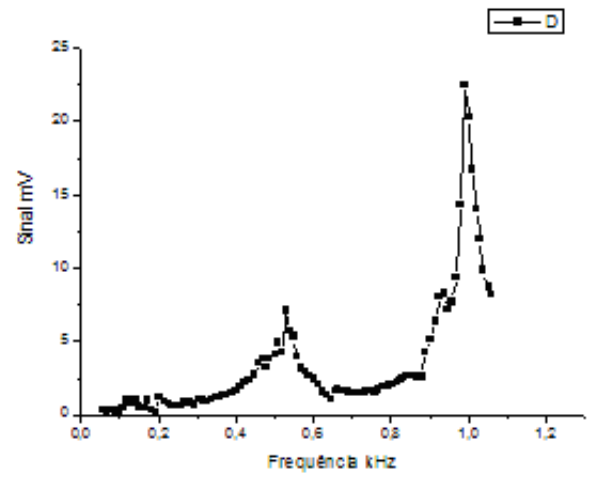

Figura 3.14: Primeira medida com a amostra (12/09/2005).

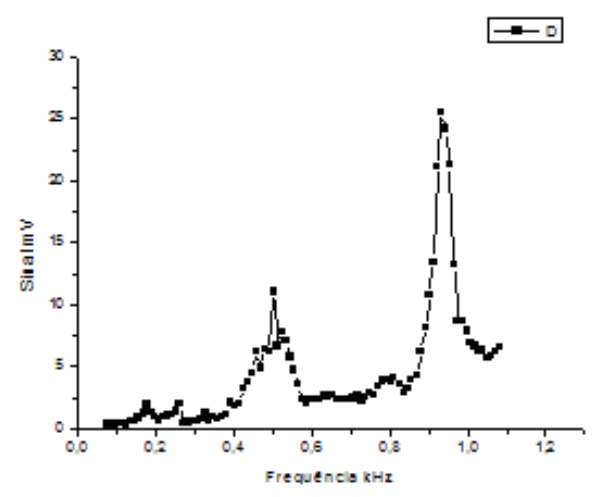

Figura 3.15: Segunda medida após uma semana $(19 / 09 / 2005)$. 


\subsection{Interferometria}

Em uma segunda tentativa de caracterizar os eletretos termo-formados, foi implementado o método por interferometria, que permite verificar o deslocamento mecânico causado pelo eletreto, quando este é submetido a uma tensão elétrica.

Através da montagem do interferômetro de Michelson como mostra a figura 3.16, pretendia-se observar a deformação da amostra mediante a aplicação de uma tensão elétrica. Através da deformação da amostra poderia-se calcular o coeficiente piezoelétrico inverso.

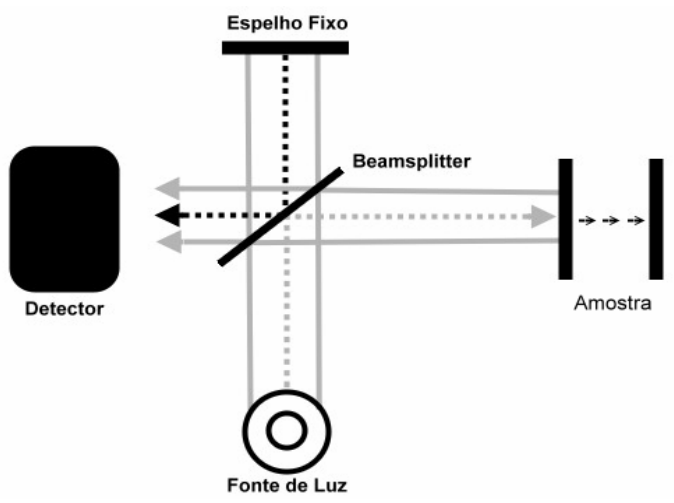

Figura 3.16: Interferômetro de Michelson.

Durante a montagem do interferômetro foi utilizado, como o espelho móvel, uma amostra metalizada. No entanto, a irregularidade da superfície da amostra impediu a obtenção das ondas de interferências, necessárias para medir o deslocamento.

Para obtê-las foi utilizado um espelho plano sobre a amostra. Essa solução alterou as propriedades físicas da amostra, devido ao peso do espelho, impossibilitando obter resultados concretos.

\subsection{Acústico direto e inverso}

Após terem sido estudadas e testadas as metodologias convencionais de caracterização do efeito piezoelétrico nos eletretos termo-formados, implementou-se um sistema acústico que fornece as características diretas e inversas. Neste contexto, no método inverso, empregou-se o mesmo programa computacional para o controle 
do Lock-in, denominado Sistema de Aquisição Lock-in SR510, e no método direto, elaborou-se um novo programa que também controla um osciloscópio da Tektronix modelo TDS-210, denominado Sistema de Aquisição TDS210-SR510, ambos melhor descritos no capítulo 4.

\subsubsection{Método acústico direto}

Na caracterização acústica direta, ou seja, o eletreto respondendo como um sensor piezoelétrico, foi utilizado um tweeter similar aqueles encontrados em computadores digitais, um gerador de áudio da Tektronix CFG253, um amplificador Lock-in da Stanford Research modelo SR 510 e um decibelímetro digital Minipa, (IEC 651 type II, Brazil). O tweeter foi alimentado por um sinal senoidal, com tensão de aproximadamente $4 \mathrm{~V}$ e freqüências na faixa de 100 a $12.000 \mathrm{~Hz}$.

A onda acústica produzida pelo tweeter foi captada simultaneamente pelo sensor e pelo decibelímetro, ambos posicionados a uma distância de $20 \mathrm{~mm}$ do tweeter como mostra a figura 3.17 .

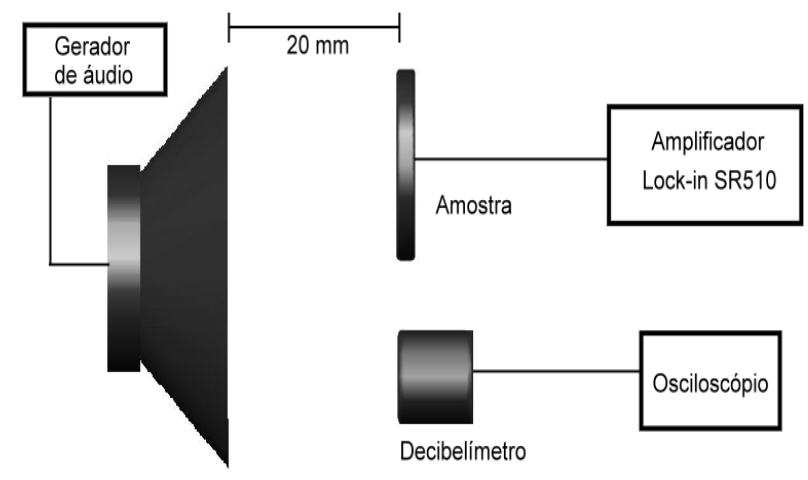

Figura 3.17: Método de medida acústico direto.

O sinal do sensor foi coletado com o Lock-in e o sinal do decibelímetro, pelo osciloscópio digital. A aquisição dos dados desses equipamentos foi realizada com o software Sistema de Aquisição TDS210-SR510, que garante uma maior uniformidade na aquisição dos dados. 


\subsubsection{Método acústico inverso}

Com os mesmos equipamentos descritos no método direto, foi também possível caracterizar as amostras inversamente. Neste caso, o sensor piezoelétrico sob ensaio, foi excitado com sinais senoidais de valor RMS 7,94 V e freqüências variando de 100 a $12.000 \mathrm{~Hz}$. O sinal acústico produzido pelo sensor foi captado pelo decibelímetro, conectado ao amplificador Lock-in. Nesta montagem, o sensor ficou posicionado a uma distância de $1 \mathrm{~mm}$ do decibelímetro. Os sinais do Lock-in foram coletados, armazenados e processados pelo Sistema de Aquisição Lock-in SR510. A figura 3.18 mostra uma representação dessa montagem.

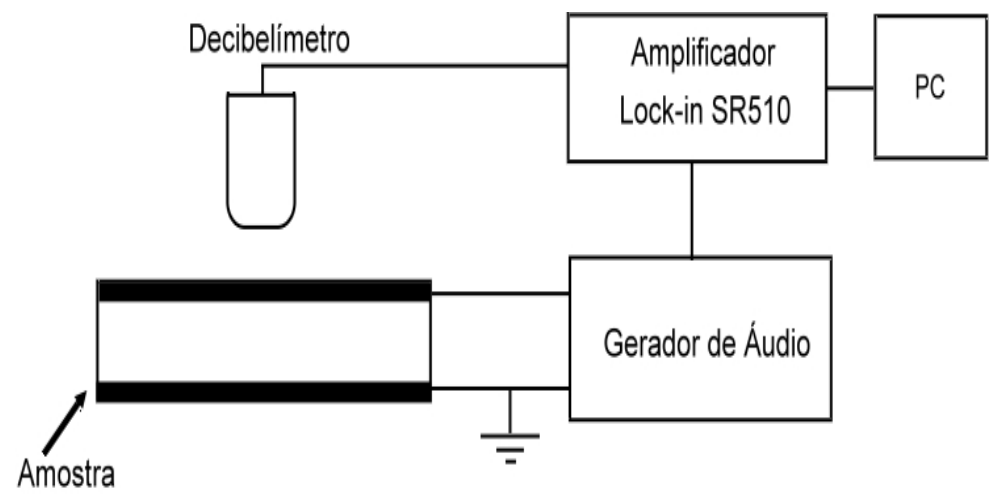

Figura 3.18: Método de medida acústico inverso.

As medidas acústicas foram realizadas em um ambiente silencioso, para evitar que qualquer ruído externo provocasse alterações nas medidas. No entanto, as fontes de alimentação dos equipamentos envolvidos acabaram por produzir ruídos indesejáveis que podem ter influenciado as medidas.

Para aprimorar o sistema acústico de medição, substituiu-se o tweeter, por um modelo profissional da Selenium - ST300, e construiu-se uma caixa acústica em formato cúbico com dimensões de 60x60x60 $\mathrm{cm}$.

Os materiais empregados na construção da câmara anecóica foram: na parte externa, o Medium Density Fiberboard (MDF) de $18 \mathrm{~mm}$ de espessura, e na parte interna, completando o revestimento, uma camada de $6 \mathrm{~cm}$ de espuma de massa específica D45 $\left(45 \mathrm{~kg} / \mathrm{m}^{3}\right)$ da Ortobom e outra camada de $6 \mathrm{~cm}$ com espuma tipo "casca de ovo" da Luckspuma com massa específica D28 $\left(28 \mathrm{~kg} / \mathrm{m}^{3}\right)$, resultando em um espaço 
útil interno de $35 \times 35 \times 35 \mathrm{~cm}$. Nas figuras 3.19 e 3.20 podem ser vistos detalhes desta caixa de medição.

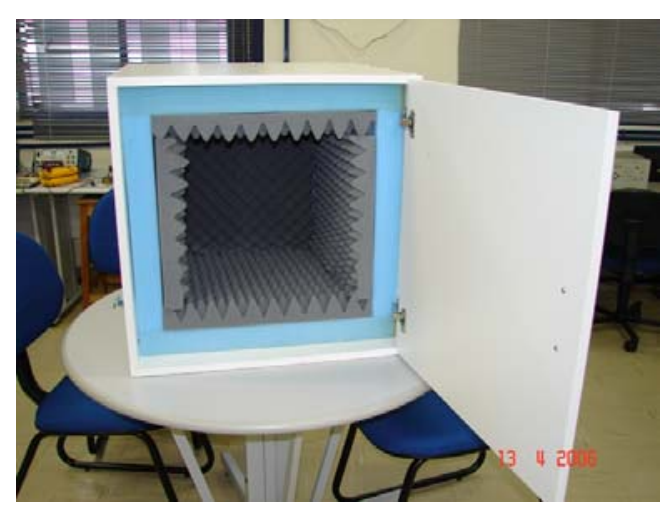

Figura 3.19: Foto da caixa acústica.

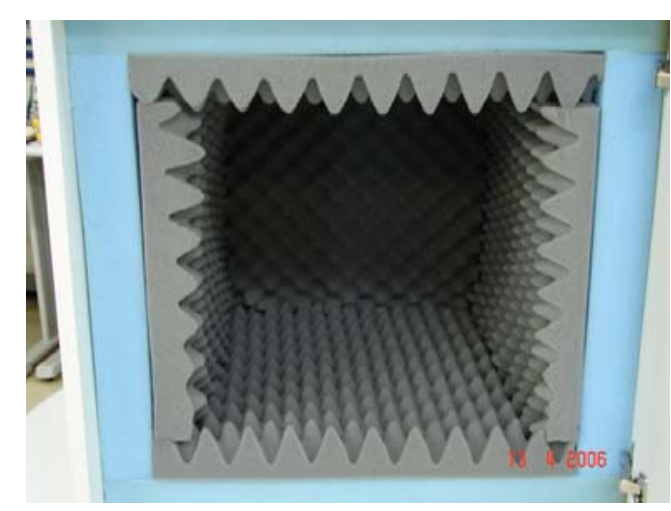

Figura 3.20: Foto da caixa acústica.

A caixa acústica embora ainda não tenha sido completamente validada, apresentou consideráveis melhoras na redução de ruídos externos durante o processo de medida, e podem ser vistos no capítulo de resultados. 


\section{Capítulo 4}

\section{Programas Computacionais para}

\section{Aquisição de Dados}

O processo de aquisição de dados, normalmente permite controlar o tempo de aquisição e armazenar os dados e alguns equipamentos de medida também possibilitam apresentar os resultados na forma de gráficos ou de tabelas.

Procurando desenvolver um sistema de aquisição de dados que possuísse essas características e que fosse aberto aos usuários e não necessitasse da compra anual de licenças de utilização, como é o caso do LaBView, foram elaborados dois programas computacionais em linguagem de programação PASCAL orientada a objetos, própria da ferramenta de desenvolvimento da Borland, Delphi 4. Esses programas foram denominados Sistema de Aquisição Lock-in SR510 e o Sistema de Aquisição TDS210-SR510.

Esses dois programas vieram auxiliar sobremaneira o processo de coleta de dados, anteriormente efetuados manualmente no Lock-in da Stanford Research.

\subsection{Sistema de Aquisição Lock-in SR510}

O Sistema de Aquisição Lock-in SR510 foi desenvolvido para controlar as funções do Lock-in amplifier SR510, realizar a aquisição e o armazenamento dos dados obtidos e produzir gráficos para análises dos resultados. Uma visão da tela principal do programa encontra-se na figura 4.1.

O programa foi projetado inicialmente para obter máxima precisão no sis- 


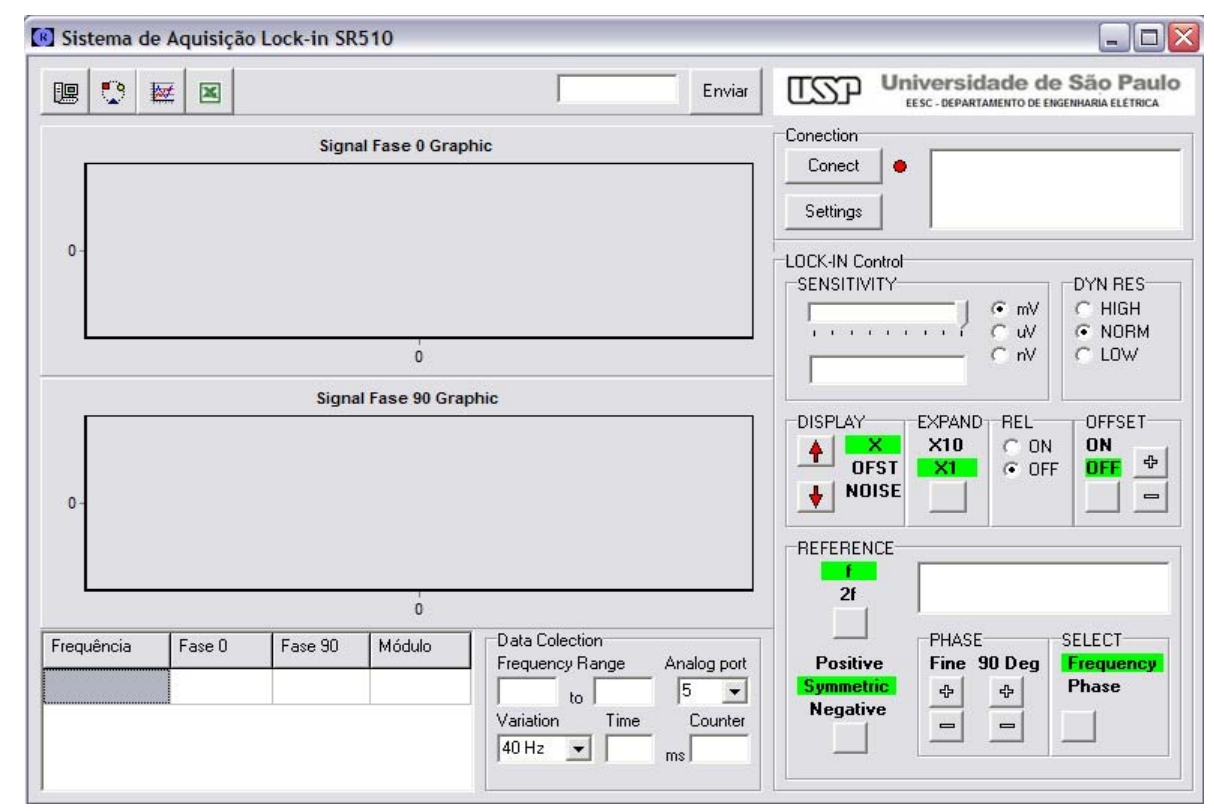

Figura 4.1: Tela principal do programa de aquisição.

tema de aquisição. Para isso, foi utilizado o oscilador interno do Lock-in como gerador de sinais senoidais com freqüência variável e amplitude máxima de 2 Volts e como sinal de referência no processo de aquisição. A comunicação entre o Lock-in e o microcomputador foi feita pela porta serial, com formato RS-232, através de um cabo serial do tipo nullmodem de 9 por 25 pinos.

Os comandos digitais de controle e aquisição do Lock-in foram fornecidos pelo fabricante no manual de operações do equipamento (THINKSRS, 2006). Esses comandos foram previamente testados através do programa computacional HyperTerminal, disponível no sistema operacional Microsoft Windows XP.

Terminada a fase de testes, desenvolveu-se a sub-rotina de controle do Lockin, com o componente de programação COMport (DELPHI, 2006), que possibilita a transmissão e recepção de dados pela porta serial. Esse componente também permitiu implementar funções de configuração exclusiva da porta serial. A comunicação com o usuário (interface) desses comandos podem ser visualizadas na tela apresentada na figura 4.2 .

O sistema de aquisição foi desenvolvido de forma que o usuário especifique a faixa de freqüência de aquisição, a taxa de amostragem, e o intervalo entre as aquisições. Essas funções foram implementadas segundo a interface gráfica ilustrada na figura 4.3. 


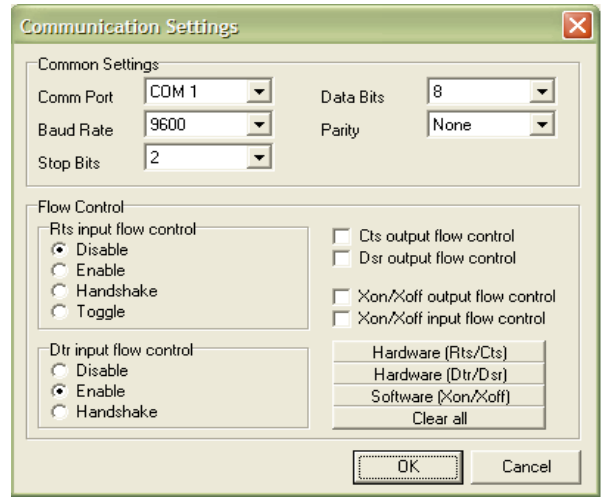

Figura 4.2: Tela de configuração da comunicação serial.

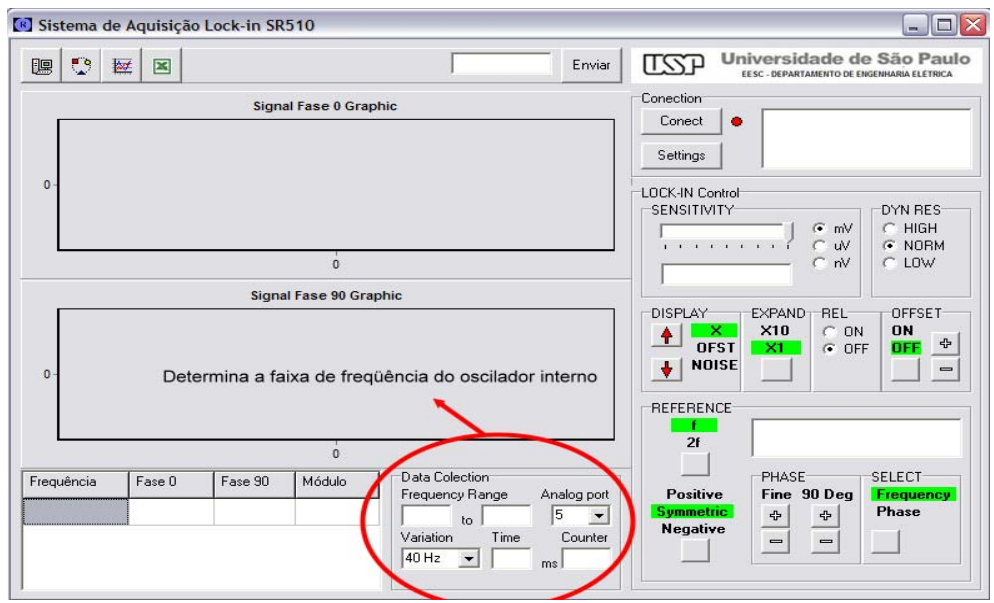

Figura 4.3: Coleta de dados utilizando o oscilador interno Lock-in.

Como proteção do sistema de aquisição, foi criada uma sub-rotina que impede a execução de qualquer comando, sem que antes esteja estabelecida a conexão entre o microcomputador e o Lock-in. Estabelecida a comunicação o programa realiza uma pré-configuração das principais funções do Lock-in, deixando pronto para aquisição.

Todos os comandos do programa foram escritos em inglês para evitar malentendidos pelos usuários acostumados com a operação do equipamento.

Durante os testes do programa, com o método dinâmico direto automatizado, observou-se que a amplitude máxima de 2 Volts era insuficiente para excitar o altofalante do sistema. Esse problema foi solucionado com a reestruturação parcial do programa, adaptando-o para também controlar um gerador de áudio da Tektronix CFG253 capaz de gerar um sinal amplificado de até 20 Volts pico a pico. Ressaltase que esta alteração acarretou na redução da sensibilidade do sistema de aquisição, 
dificultando ajustes iniciais dos parâmetros de freqüência.

Além das alterações no programa também foram necessários ajustes no gerador de áudio e modificações nas conexões do Lock-in. As conexões do Lock-in foram modificadas de forma que a saída analógica (Analog outputs) X5, que fornece um sinal DC proporcional a freqüência, fosse conectada na entrada VCF input do gerador de áudio. O resultado desta configuração foi obter um sinal variável em freqüência amplificado e totalmente controlado pelo computador. Completando os ajustes necessários, o botãosweep do gerador de áudio foi posicionado para controle externo e o botão de ajuste manual de freqüência posicionado no fim de curso.

Para facilitar a operação de aquisição com gerador de áudio foi desenvolvida uma nova tela de configuração vista na figura 4.4, que surge quando essa operação é requisitada. Nesta tela, a faixa de varredura, a taxa de amostragem (Range) e o tempo que se deseja executar cada aquisição podem ser especificados pelo operador através de valores pré-definidos, o que evita erros na operação.

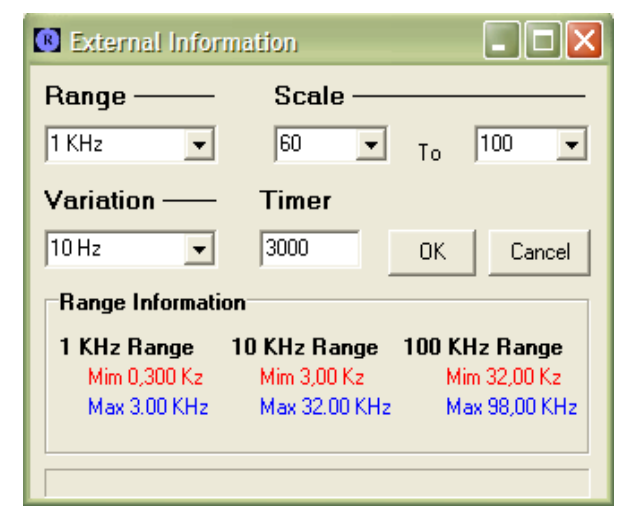

Figura 4.4: Tela de configuração para aquisição de dados com o gerador de frequência.

Cada uma das operações executadas pelo programa foi disponibilizada por um botão posicionado no canto esquerdo superior da barra de ferramentas. Estes botões conforme mostram as figuras 4.5, 4.6, 4.7 e 4.8 possuem respectivamente as seguintes funções: iniciar a aquisição com oscilador interno, iniciar a aquisição com o gerador de áudio, plotar os resultados em forma de gráficos e exportar os dados para o aplicativo Excel da Microsoft. 


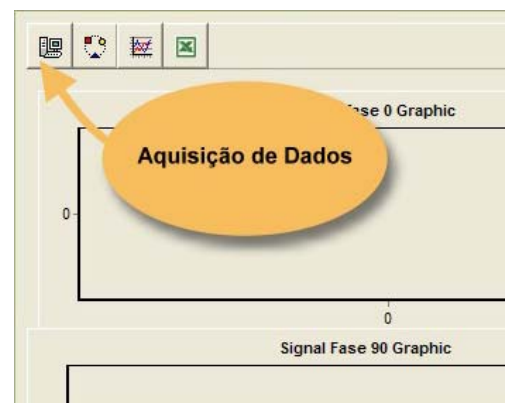

Figura 4.5: Botão para aquisição de dados utilizando somento o Lock-in.

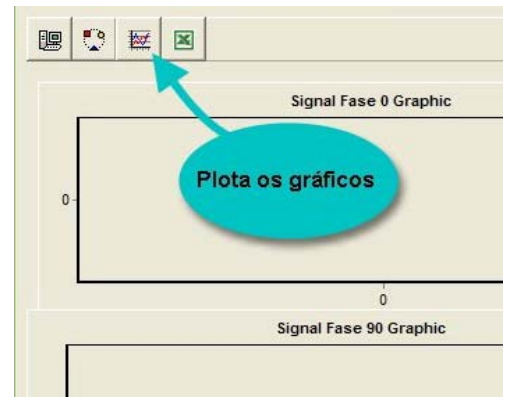

Figura 4.7: Botão para plotar os resultados em forma de gráficos.

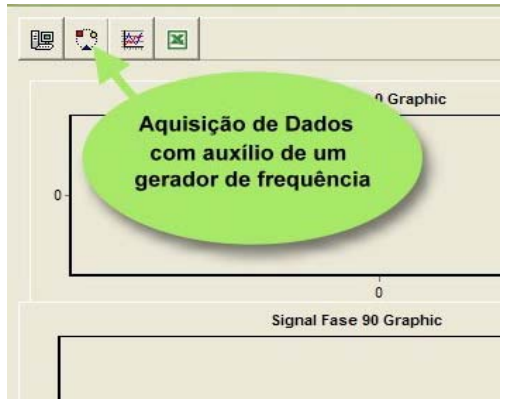

Figura 4.6: Botão de aquisição utilizando o gerador de frequência.

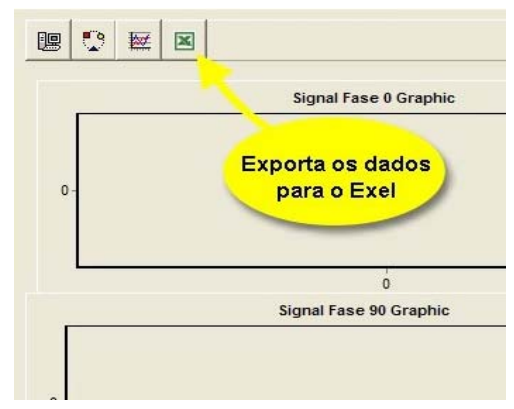

Figura 4.8: Botão para exportar os dados para o Microsoft Excel.

Na finalização do processo de aquisição, os resultados são apresentados na tabela conforme a figura 4.9 e podem ser visualizados na forma de gráficos ou exportados para outras análises com os comandos das figuras 4.7 e 4.8.

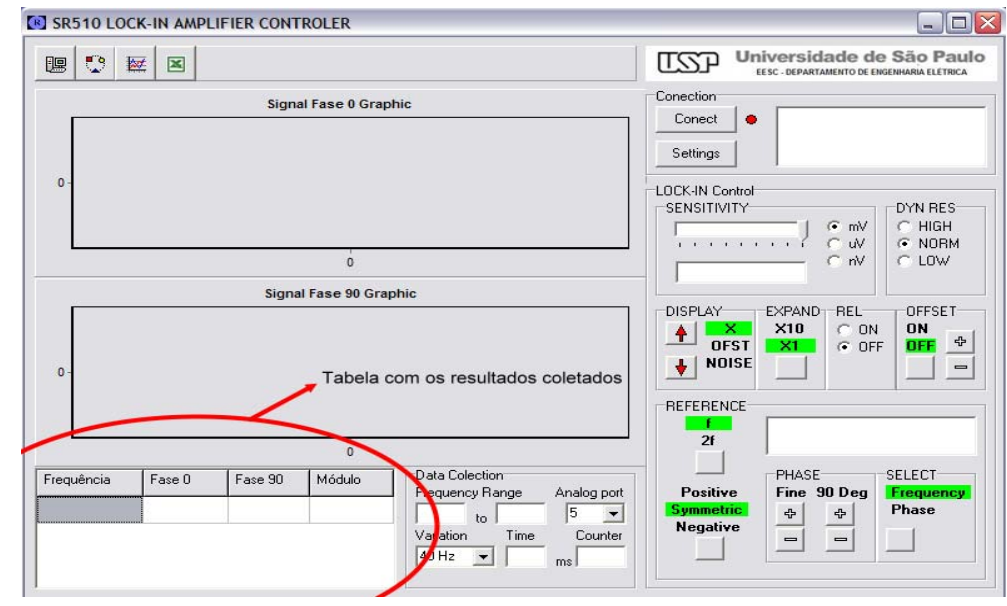

Figura 4.9: Tabela para exibição dos resultados coletados. 
Assim, o desenvolvimento do Sistema de Aquisição Lock-in SR510 tornou possível a implementação de um sistema totalmente controlado por computador e que assegura uma aquisição de dados do método dinâmico direto e do método acústico inverso.

Para o processo de medida do método acústico direto, que exige a aquisição de sinais de duas fontes externas (microfone e amostra), o Lock-in torna-se insuficiente por possuir apenas um canal de entrada. A solução para o problema foi encontrada adicionado-se um novo equipamento ao sistema, o osciloscópio digital Tektronix TDS210.

Contudo a presença desse osciloscópio, implicou na elaboração de um novo programa capaz de controlar tanto a aquisição dos dados do Lock-in quanto do osciloscópio e ainda controlar a varredura de freqüência do gerador de áudio. Esse aplicativo foi denominado Sistema de Aquisição TDS210-SR510 e é apresentado no item subseqüente.

\subsection{Sistema de Aquisição TDS210-SR510}

O Sistema de Aquisição TDS210-SR510, cuja tela principal pode ser vista na figura 4.10, foi projetado para garantir ao usuário controle do sistema de aquisição do osciloscópio. Os tipos de aquisição implementados foram RMS (Root Mean Square), Pico a Pico ou média aritmética.

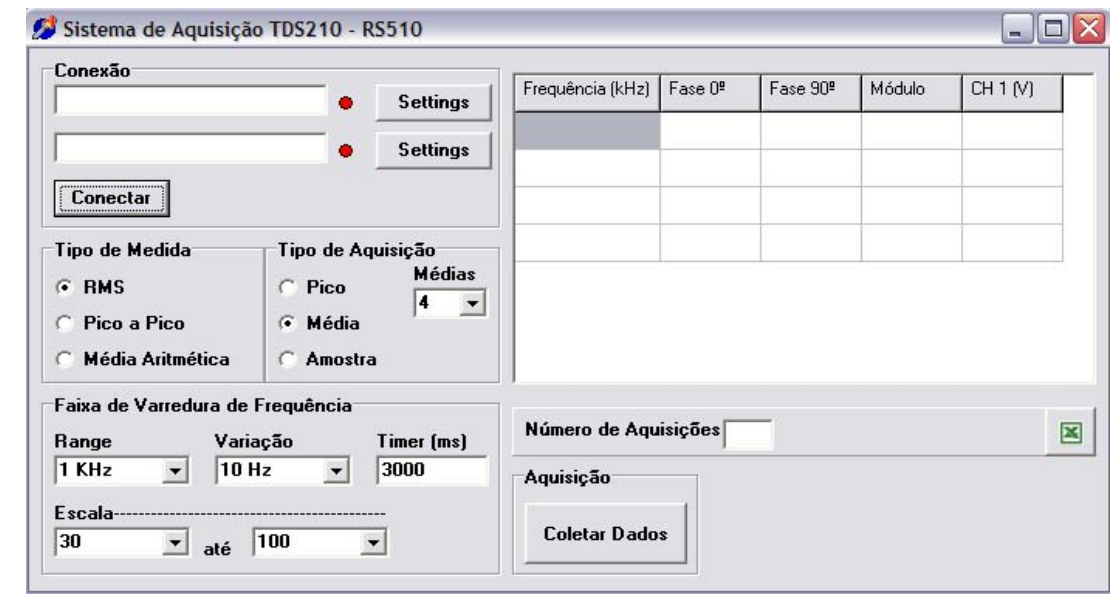

Figura 4.10: Tela principal do Sistema de Aquisição TDS210-SR510. 
A linguagem de programação utilizada também foi o Pascal orientado a objetos, própria da ferramenta de desenvolvimento da Borland, Delphi 4. Esta ferramenta de programação foi mantida em função de sua flexibilidade e reutilização de sub-rotinas já implementadas no controle do Lock-in e do gerador de áudio.

A comunicação com o componente COMport, já havia se mostrado bem funcional e também foi mantida por permitir o controle de várias portas seriais. A única diferença para a comunicação com o osciloscópio foi o cabo serial, que neste caso passou a ser do tipo nullmodem de 9 por 9 pinos. Isto por que a entrada RS-232 do osciloscópio requer esse tipo de conector. Os mesmos testes de conexão e dos comandos encontrados no manual do equipamento (TEKTRONIX, 2006), foram também efetuados com o programa Hiper-terminal.

O método de seleção da faixa de freqüência, a possibilidade de exportar os dados armazenados para o programa Excel e a forma como os resultados são apresentados foram mantidas idênticas as do Sistema de Aquisição Lock-in SR510, facilitando sua utilização pelo usuário. 


\section{Capítulo 5}

\section{Resultados}

Embora tenham sido implementados quatro métodos de caracterização, o método dinâmico direto, o método por interferometria e os métodos acústicos, direto e inverso, apenas os resultados dos métodos acústicos serão apresentados neste capítulo. Uma vez que o método dinâmico direto ainda precisa ser calibrado para atingir os objetivos esperados de caracterização, e o método por interferometria por não ter apresentado resultados quantitativos, também não será mencionado.

Também se enfatiza que conjuntamente com os resultados apresentados, serão discutidos os problemas encontrados e sugestões para aprimoramentos futuros.

Os resultados dos métodos acústicos foram divididos em duas partes. A primeira parte apresenta os resultados obtidos em um sistema desenvolvido para ambientes silenciosos e a segunda, os resultados obtidos com o emprego de uma caixa acústica.

\subsection{Método acústico em ambiente silencioso}

As primeiras medidas foram realizadas com os métodos acústicos direto e inverso em ambiente silencioso, empregando amostras de $2,4 \mathrm{~cm}$ de diâmetro e filmes de Teflon-FEP de $75 \mu m$ no formato indicado na figura 5.1.

O sistema foi calibrado excitando-se o tweeter com sinais senoidais de amplitude 2 Volts e freqüências variando de 100 até $12.000 \mathrm{~Hz}$ e medindo-se o som produzido com o decibelimetro Minipa modelo IEC-651 type II, a uma distância de $20 \mathrm{~mm}$ do tweeter. A curva de ponderação em freqüência do decibelímetro usada, foi a do tipo 


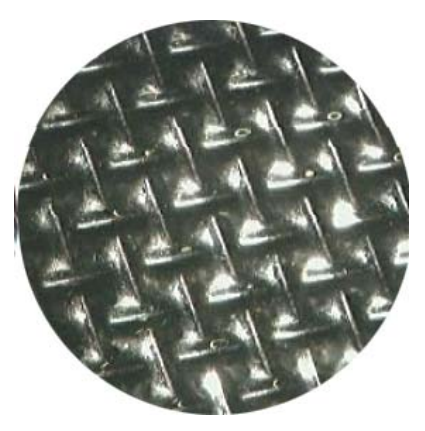

Figura 5.1: Formato da amostra utilizada na caracterização acústica

C conforme especificado pelo fabricante (MINIPA, 2006) e encontra-se em anexo. Os resultados dessa caracterização podem ser visualizados nas figura 5.2 e 5.3.

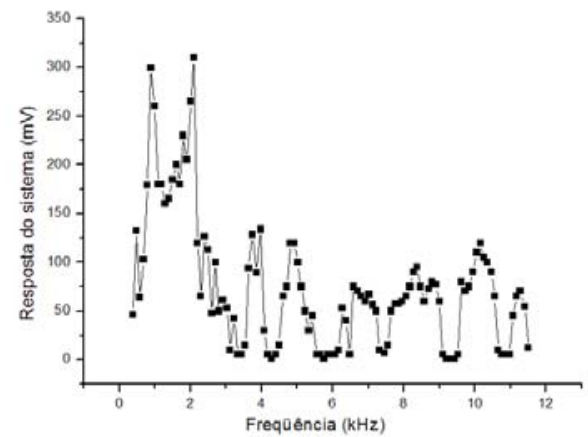

Figura 5.2: Relação entre sinal de saída em $m V$ do tweeter pela freqüência.

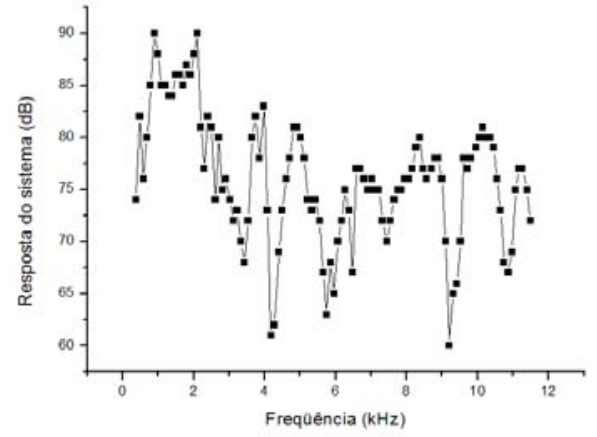

Figura 5.3: Relação entre sinal de saída em $d B$ do tweeter pela freqüência.

Embora os resultados apresentem valores para freqüências acima de $8 \mathrm{kHz}$, esses valores superiores devem ser interpretados com cuidado uma vez que a freqüência de operação do decibelímetro limita-se a 8 kHz.

\subsubsection{Método acústico direto}

Neste método o decibelímetro e a amostra foram posicionados a uma distância de $20 \mathrm{~mm}$ do tweeter. Depois de determinada a resposta do sistema, as ressonâncias intrínsecas do sistema foram identificadas e subtraídas dos resultados. Esses resultados finais obtidos com o método direto podem ser observados na figura 5.4. 


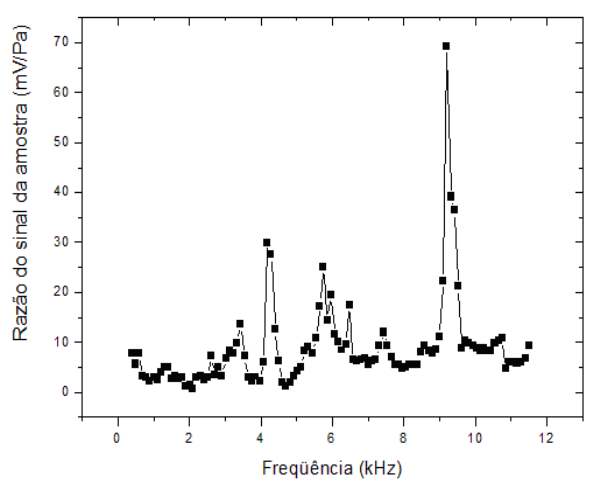

Figura 5.4: Relação entre a razão do sinal da amostra $m V / P a$ pela freqüência no método acústico direto.

\subsubsection{Método acústico inverso}

O sistema acústico inverso foi implementado excitando-se a amostra com sinais senoidais de 7,94 Volts RMS e freqüências entre $100 \mathrm{~Hz}$ e $12 \mathrm{kHz}$. A distância entre a amostra e o decibelímetro foi mantida em $1 \mathrm{~mm}$. Com isto, foram obtidas respostas similares àquelas observadas na figura 5.5. Esses resultados estão condizentes com aqueles obtidos por outros autores empregando o mesmo método (WEINHOLD et al., 2000); (HILLENBRAND \& SESSLER, 2004b).

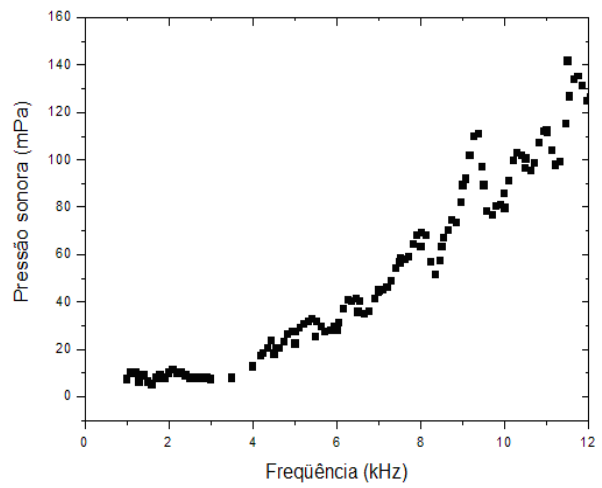

Figura 5.5: Relação entre a freqüência e a pressão acústica exercida pela amostra no método acústico inverso. 
Esses resultados preliminares mostraram que os métodos acústicos executados em ambiente silencioso podem ser empregados apenas qualitativamente.

\subsection{Método acústico em câmara fechada}

Para minimizar os ruídos inerentes no método anterior, foi construída uma câmara acústica apresentada no capítulo 3. Esta proporcionou uma redução de ruído de 55 decibel (dB) para um nível de ruído de apenas 34 (dB). Também observou-se que ruídos externos como toque de telefone, conversas e etc, não afetaram as medidas dentro da câmara. Essas melhorias proporcionadas pela caixa acústica e mais a aquisição de um novo tweeter, permitiram que algumas medidas quantitativas fossem efetuadas. Antes, porém foi necessário caracterizar novamente o sistema.

As figuras 5.6 e 5.7 mostram relações entre a pressão acústica e a freqüência do tweeter no sistema de caracterização do fabricante e no nosso sistema respectivamente.

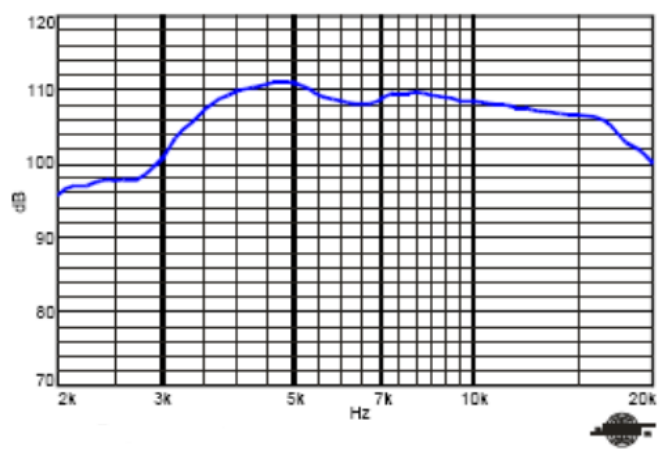

Figura 5.6: Relação entre freqüência e pressão acústica do tweeter ST300 da Selenium (SELENIUM, 2006).

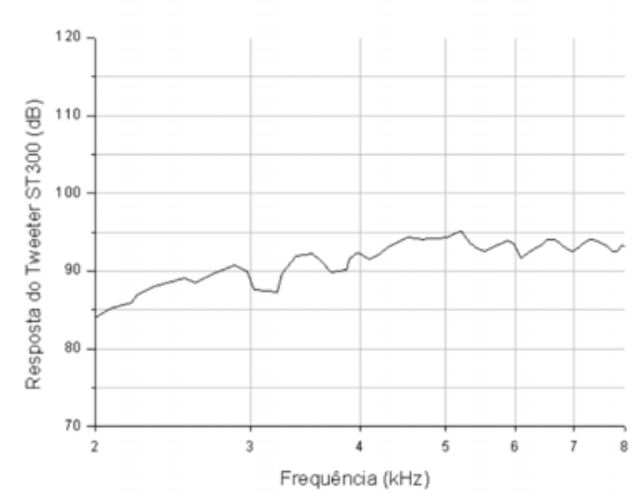

Figura 5.7: Relação entre freqüência e pressão acústica do tweeter ST300 da Selenium no sistema.

A caracterização do sistema foi realizada posicionando-se o tweeter a uma distância de $110 \mathrm{~mm}$ do decibelímetro e excitando-o com um sinal senoidal de $2 \mathrm{~V}$ pico a pico. As medidas acústicas foram obtidas diretamente pelo decibelímetro.

As medidas acústicas nesse novo sistema foram realizadas com amostras de apenas uma bolha de $4 \mathrm{~mm}$ de diâmetro como mostra a figura 5.8. Essas amostras foram montadas com filmes de Teflon-FEP de $50 \mu m$ e metalizadas com alumínio. 


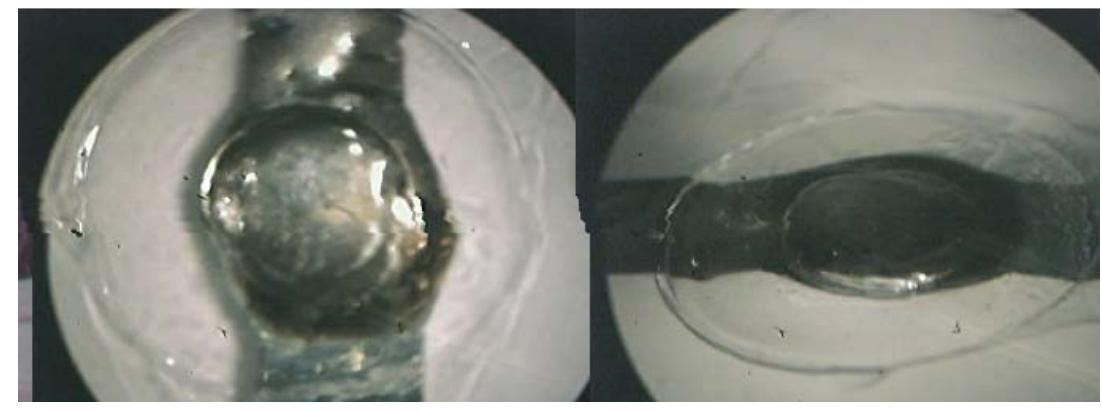

Figura 5.8: Amostra de Teflon-FEP com uma bolha de $4 \mathrm{~mm}$ de diâmetro.

A montagem do sistema direto foi feita com a amostra e o decibelímetro, posicionados a uma distância de $110 \mathrm{~mm}$ do tweeter, que também foi alimentado com uma tensão de $2 V$ pico a pico, para essa medida.

Os resultados do método acústico direto obtidos com essas amostras e sem as ressonâncias do sistema, encontram-se na figura 5.9.

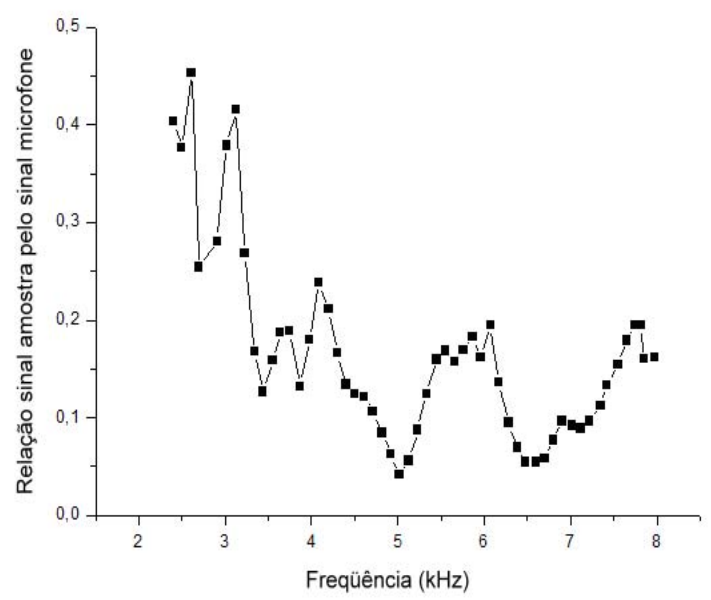

Figura 5.9: Relação sinal da amostra pelo sinal do microfone em função da freqüência para uma amostra com uma única bolha.

No entanto, durante esse processo de medida, foi observado que o alto-falante utilizado produz um ruído de indução magnética perceptível pelo decibelímetro. Logo ajustes deverão ser realizados a fim de eliminar esses sinais indesejados.

Utilizando as mesmas amostras com uma única bolha, foram realizadas me- 
didas inversas, excitando a amostra com um sinal senoidal de 7,94 $\mathrm{V}$, a uma distância de $25 \mathrm{~mm}$ do decibelímetro. Com isso obteve-se os resultados apresentados nas figuras 5.10 e 5.11 .

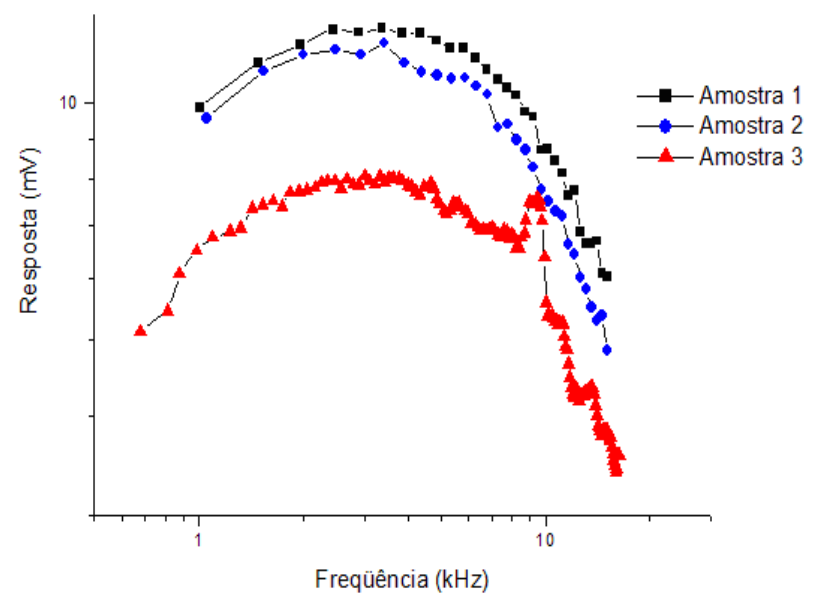

Figura 5.10: Relação entre a resposta da amostra em $m V$ pela freqüência de várias amostras com uma única bolha.

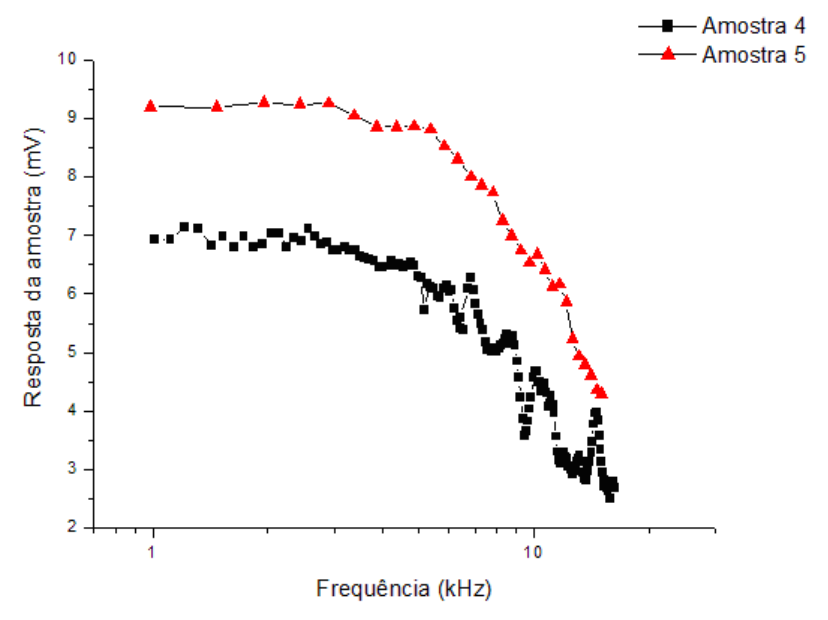

Figura 5.11: Relação do sinal da amostra em função da freqüência de várias amostras com uma única bolha.

Comparando as respostas da figura 5.10 é possível observar que apenas a amostra 3 apresenta um pico de ressonância em torno dos $9 \mathrm{kHz}$. Essa ressonância pode 
ser explicada pelo fato das amostras 1 e 2, serem formadas por filmes de Teflon-FEP de $50 \mu \mathrm{m}$ e a amostra 3 por filmes de $75 \mu \mathrm{m}$. No entanto, observou-se na figura 5.12, que a amostra 4 com filmes de Teflon-FEP de $50 \mu m$, também apresenta ressonância em uma freqüência perto dos $6,8 \mathrm{kHz}$. Isso pode ser uma indicação de que esta ressonância pode estar sendo causada pelo tipo de suporte empregado.

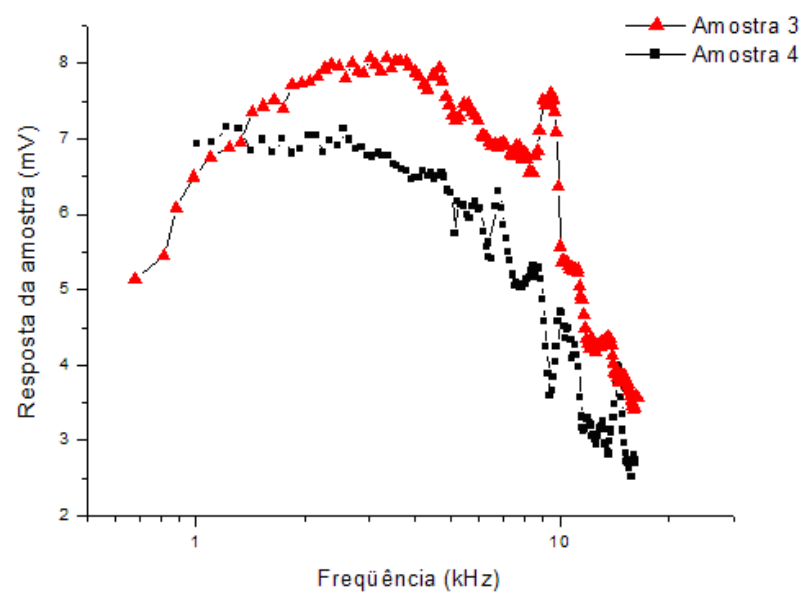

Figura 5.12: Relação dos sinais das amostras 3 e 4 em função da freqüência.

Essa observação é importante para demonstrar que alterações no suporte da amostra podem produzir resultados diferentes, uns com ressonância e outros sem. Devido a isso novos suportes devem ser implementados no futuro para eliminar esses erros.

Os resultados obtidos com essas amostras, estão sendo comparados com o modelo teórico desenvolvido pelo Mestre Cláudio Vara de Aquino em seu trabalho de doutorado dentro do grupo de pesquisa sobre a orientação do professor Heitor C. Basso. Essas comparações têm mostrado que os resultados experimentais têm forte correlação com os teóricos.

Ambos os métodos acústicos, direto e inverso também serviram para ensaiar amostras de sensores múltiplas bolhas. Nesses testes foram mantidas as mesmas distâncias entre a amostra, decibelímetro e alto-falante, e também as mesmas tensões de excitação.

Os resultados da medida acústica direta podem ser observados na figura 5.13 
e os da medida acústica inversa, na figura 5.14.

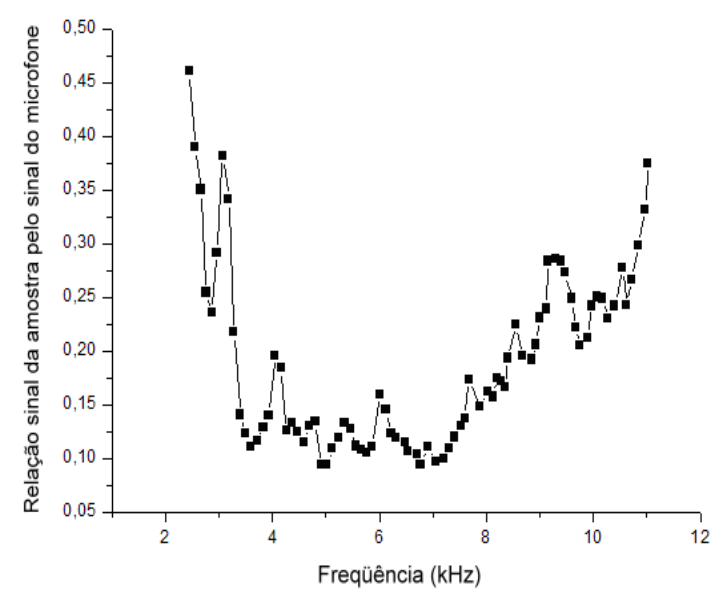

Figura 5.13: Resposta da amostra com múltiplas bolhas pelo método acústico direto.

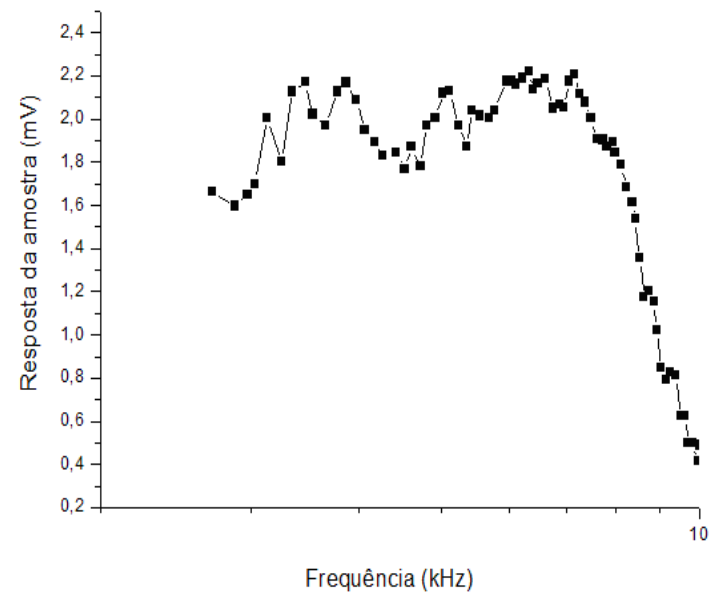

Figura 5.14: Resposta da amostra com múltiplas bolhas pelo método acústico inverso.

\subsection{Comparação entre uma e múltiplas bolhas pelo método direto}

A figura 5.15 mostra uma comparação entre uma amostra com múltiplas bolhas e uma amostra com uma única bolha. Esse resultado mostra uma ressonância 
entre 5,4 e $6 \mathrm{kHz}$ para a amostra com uma bolha. Esse comportamento era esperado, pois uma bolha maior tende a ressoar em uma freqüência mais baixa do que uma bolha menor.

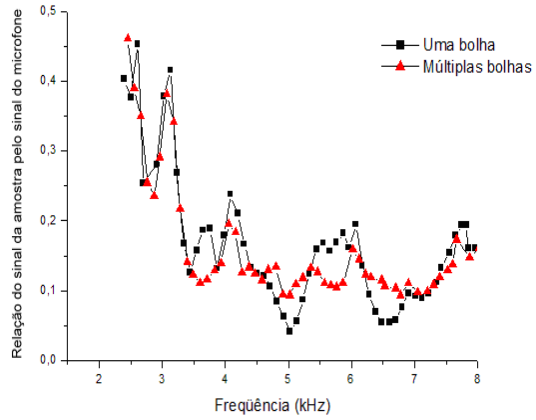

Figura 5.15: Resposta das amostras com múltiplas bolhas e das amostras com uma bolha pelo método direto.

\subsection{Comparação entre uma e múltiplas bolhas pelo método inverso}

A comparação apresentada na figura 5.16 mostra uma resposta linear no método inverso para freqüência abaixo de $6,8 \mathrm{kHz}$ para ambos tipos de amostras. No entanto observa-se novamente um pico de ressonância para a amostra com um única bolha.

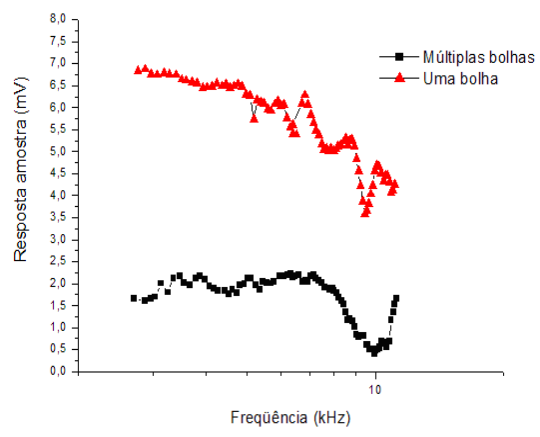

Figura 5.16: Resposta das amostras com múltiplas bolhas e das amostras com uma bolha pelo método inverso. 


\subsection{Outros resultados}

Também como resultado deste trabalho foram publicados dois artigos em congressos internacionais IEEE (ALTAFIM et al., 2005) e (BASSO et al., 2006) e um na revista IEEE-Transaction on Dielectric and Electrical Insulation (ALTAFIM et al., 2006). 


\section{Capítulo 6}

\section{Conclusões}

Embora existam diversos métodos de medidas para caracterizar os materiais piezoelétricos, poucos métodos podem ser utilizados na caracterização dos eletretos termo-formados. Nesses eletretos, o princípio físico encontra-se fundamentado nas variações de dipolos com dimensões nanométricas ou mesmo micrométricas e não em dipolos moleculares como ocorre na maioria dos demais materiais piezoelétricos. Assim, para caracterizar esses eletretos foram selecionados quatro métodos que eram exeqüíveis com as condições laboratoriais existentes, os métodos acústicos, direto e inverso, o método óptico e o método dinâmico direto.

Contudo, no decorrer da pesquisa observou-se que os equipamentos disponíveis apresentavam inúmeras limitações e embora tenham sido implementados quatro métodos, apenas dois deles, os métodos acústico apresentados no capítulo 5, mostraramse viáveis para a caracterização dos eletretos termo-formados.

Os métodos acústicos desenvolvidos permitem que as amostras sejam caracterizadas tanto diretamente como inversamente. O cerne do controle desses métodos consiste em dois programas computacionais especialmente elaborados em linguagem PASCAL, orientada para objetos, no ambiente de desenvolvimento DELPHI 4 da Borland. Esses programas têm como característica principal o controle de todos os equipamentos envolvidos, a exemplo do amplificador Lock-in, do osciloscópio e do gerador de áudio, de todo o processo de aquisição e do armazenamento dos dados. O que torna automático todo o processo de aquisição. Também é parte integrante destes programas a visualização gráfica e tabelada dos resultados. Além de permitirem a exportação 
dos dados para outros ambientes, a exemplo do Excel. Ressalta-se ainda, que esses programas também permitiram o desenvolvimento de um Know-how em sistemas de aquisição e controle computacional de equipamentos, assegurando no futuro uma significativa redução no pagamento de licenças.

Para melhorar os métodos acústicos ainda foi construído uma câmara acústica que reduziu significativamente a influência de ruídos externos durante o processo de medida. Sugere-se ainda que no futuro seja adquirido um novo microfone capaz de realizar medições além dos $8 \mathrm{kHz}$, para que seja possível detectar outras ressonâncias intrínsecas dos eletretos termo-formados.

No método óptico, a superfície metalizada das bolhas mostrou-se insuficiente para refletir a luz do laser. Esse problema foi solucionado colocando-se espelhos refletores sobre as bolhas. Ao realizar isso, observou-se pequenos movimentos das franjas de interferência, que poderiam ser avaliados por fotodetectores.

Contudo, esse experimento foi temporariamente abandonado, porque o peso dos espelhos sobre as bolhas, causaram erros significativos nas medidas.

O sistema dinâmico também implementado no início deste trabalho com algumas modificações, pode ser calibrado através de equipamentos apropriados, tornando-se um método de medida extremamente barato e eficiente. Contudo, ele atualmente tem se prestado para informações qualitativas sobre a existência do efeito piezoelétrico nos eletretos termo-formados.

Concluindo, acredita-se que os objetivos deste trabalho foram satisfatoriamente atingidos com a análise de diversos métodos que hoje são utilizados para caracterizar polímeros piezoelétricos e a implementação completa de um desses métodos de caracterização dinâmica. Enfatiza-se entretanto, que as pesquisas devem continuar buscando ampliar a faixa de freqüência do método implementado e investigar com mais detalhes a influência dos suportes e as ressonâncias dos eletretos termo-formados. 


\section{Referências Bibliográficas}

(ALtAfim et al., 2006). Altafim, R. A. C., Basso, H. C., Altafim, R. A. P., Lima, L., Aquino, C. V., Neto, L. G., e Gerhard-Multhaupt, R. Piezoelectrets from thermoformad bubble structures of fluoropolymer-electret films. IEEE-Transaction on Dielectric and Electrical Insulation, Under publication, 2006.

(AltAFim et al., 2005). Altafim, R. A. C., Basso, H. C., Neto, L. G., Lima, L., Altafim, R. A. P., e Aquino, C. V. Piezoelectricity in multi-air voids electrets. IEEE Annual Report Conference on Electrical Insulation and Dielectric Phenomena, pages 669$672,2005$.

(ALTAFIM et al., 2003). Altafim, R. A. C., Dias, C., Neto, L. G., Basso, H. C., Murakami, C., Veronese, P. R., e Rodrigues, E. F. Piezoelectricity of multi-layers spacecharge electrets from Teflon FEP film with homogeneous voids distributed on its surface. IEEE Annual Report Conference on Electrical Insulation and Dielectric Phenomena, pages 225-228, 2003.

(ALTAFIM et al., 1992). Altafim, R. A. C., Giacometti, J. A., e Janiszewski, J. M. A novel method for electret production using impulse voltages. IEEE Transaction on Electrical Insulation, pages 739-743, 1992.

(ANSI, 1987). ANSI. IEEE Standard on Piezoelectricitry. American National Standards Institute, 345 East 47th Street, New York, NY 10017, USA, 1987. ANSI/IEEE Std 176-1987.

(APC INTERNATIONAL, 1998). APC International, L. Constante piezoelétrica, 1998. Disponível em: 〈http://www.americanpiezo.com/piezo theory/ piezoelectric constants.html> Acesso em: 08 de set. 
(B-BAND, 2006). B-Band. Transdutores acústicos, 2006. Disponível em: 〈http://www . b-band.com/ Acesso em: 08 de jun.

(BALLATO, 1995). Ballato, A. Piezoelectricity: old effect, new thrusts. IEEE Transactions on Ultrasonics, Ferroelectrics, and Frequency Control, 42(5):916-926, 1995.

(BALLATO, 1996). Ballato, A. Piezoelectricity: history and new thrusts. IEEE Ultrasonics Symposium, pages 575-583, 1996.

(BASSO et al., 2006). Basso, H. C., Aquino, C. V., Altafim, R. A. P., Altafim, R. A. C., e Gerhard-Multhaupt, R. Piezoelectricity of a single bubble formed by two oppositely charged Teflon-FEP films. IEEE Annual Report Conference on Electrical Insulation and Dielectric Phenomena, page under publication, 2006.

(DELPHI, 2006). Delphi, P. Download do componente ComProt para o Delphi4, 2006. Disponível em: 〈http://www.inf.ufsc.br/ prass/ Acesso em: 20 de jun.

(DREYFUS \& LEWINER, 1973). Dreyfus, G. e Lewiner, J. Piezoelectricity induced by charge injection in polymer films. Electrets, Charge Storage and Transport in Dielectrics, ed. by M. M. Perlman. The Electrochemical Society, pages 517-528, 1973.

(DUPONT, 2005). Dupont. Características do Teflon FEP, 2005. Disponível em: 〈http: //www.dupont.com/teflon/films/H-55008-2.html> Acesso em: 01 de set.

(EMFIT, 2006). Emfit. Sensores de monitoramento, 2006. Disponível em: 〈http://www . emfit.com/ Acesso em: 08 de jun.

(FUKADA, 2000). Fukada, E. History and recent progress in piezoelectric polymers. IEEE Transactions on Ultrasonics, Ferroelectrics, and Frequency Control, 47(6):12771290, 2000.

(GERHARD-MULTHAUPT, 2002). Gerhard-Multhaupt, R. Less can be more - Holes in polymer lead to a new paradigm of piezoelectric materials for electret transducers. IEEE Transactions on Dielectric and Electrical Insulation, 9(5):850-859, 2002.

(GERHARD-MULTHAUPT et al., 2000). Gerhard-Multhaupt, R., Wegener, M., Künstler, W., Wirges, W., Görne, T., Urayama, K., e Neher, D. Inverse piezoelectricity of 
porous PTFE films with bipolar space charge. Conference on Electrical Insulation and Dielectric Phenomena, pages 377-380, 2000.

(GERHARD-MULTHAUPT et al., 1999). Gerhard-Multhaupt, R., Xia, Z., Künstler, W., e Pucher, A. Preliminary study of multi-layer space-charge electrets with piezoelectric properties from porous and non-porous Teflon $\AA$ films. 10th International Symposium on Electrets, IEEE Service Center, pages 273-276, 1999.

(GüNTHER et al., 1993). Günther, P., Ding, H., e Gerhard-Multhaupt, R. Electret properties of spin-coated Teflon-AF films. Conference on Electrical Insulation and Dielectric Phenomena, pages 197-202, 1993.

(GOEL, 2003). Goel, M. Electret sensors, filters and MEMS devices: New challenges in materials research. Current Science, 85(4):443-453, 2003.

(HALLIDAY \& RESNICK, 1975). Halliday, D. e Resnick, R. Física II, chapter 30, pages 112-121. Livros técnicos e científicos editora S.A., Rio de Janeiro, RJ, 1975.

(HAYAKAWA \& WADA, 1971). Hayakawa, R. e Wada, Y. A general description of piezoelectricity of polymer films. Reports on Progress in Polymer Physics in Japan, 14:467-470, 1971.

(HAYAKAWA \& WADA, 1973). Hayakawa, R. e Wada, Y. Piezoelectricity and related properties of polymer films. Advances in Polymer Science, 11:1-55, 1973.

(HAYAKAWA \& WADA, 1976). Hayakawa, R. e Wada, Y. Piezoelectricity and pyroelectricity of polymer films arising from heterogeneity and embedded charges. Reports on Progress in Polymer Physics in Japan, 19:321-324, 1976.

(HILLENBRAND \& SESSLER, 2000). Hillenbrand, J. e Sessler, G. M. Piezoelectricity in cellular electret films. IEEE Transactions on Dielectric and Electrical Insulation, $7(4): 380-385,2000$.

(HILLENBRAND \& SESSLER, 2004). Hillenbrand, J. e Sessler, G. M. High-sensitivity piezoelectric microphones based on stacked cellular polymer films (L). Journal of the Acoustical Society of America, 116:3267-3270, 2004.

(HILLENBRAND \& SESSLER, 2004b). Hillenbrand, J. e Sessler, G. M. Quasistatic and dynamic piezoelectric coefficients of polymer foams and polymer film system. IEEE Transactions on Dielectric and Electrical Insulation, 11(1):72-79, 2004. 
(KIM \& KIM, 1998). Kim, D. G. e Kim, H. G. A new characterization of piezoelectric thin films. Proceedings of the Eleventh IEEE International Symposium, pages 65-68, 1998.

(KIRJAVAINEN, 1987). Kirjavainen, K. Electromechanical film and procedure for manufacturing same. US Patent, (4,654,546), 1987.

(KRESSMANN, 2001). Kressmann, R. Linear and nonlinear piezoelectric response of charged cellular polypropylene. Journal of Applied Physics, 90(7):3489-3496, 2001.

(LANG, 2005). Lang, S. B. Pyroelectricity: From ancient curiosity to modern imaging tool. Physics Today, pages 31-36, 2005.

(LIMA, 2005). Lima, L. Transdutores Piezelétricos Multicamadas de Teflon FEP com micro bolhas superficiais distribuidas uniformemente., 2005. Monografia de Qualificação de Mestrado, Escola de Engenharia - USP - São Carlos.

(MEMS \& CLEARINGHOUSE, 2001). MEMS e Clearinghouse, N. MEMS and Nanotechnology, 2001. Disponível em: 〈http://www.memsnet.org/mems/what-is.html〉 Acesso em: 14 de set.

(MINIPA, 2006). Minipa. Características do decibelímetro, 2006. Disponível em: 〈http:// www.minipa.com.br/prod esp.asp?id=124\&cod produto=MSL-1325 Acesso em: 20 de jun.

(RODRIGUES, 2003). Rodrigues, E. Novos sensores piezoelétricos com eletretos de Teflon FEP, 2003. p. Dissertação (Mestrado) - , Escola de Engenharia - USP - São Carlos.

(SAVOLAINEN \& KIRJAVAINEN, 1989). Savolainen, A. e Kirjavainen, K. Electrothermomechanical film, Part I. Design and characteristics. Journal of Macromolecular Science-Chemistry, A26:583-591, 1989.

(SCREENTEC, 2006). ScreenTec. Teclados de filmes poliméricos, 2006. Disponível em: /http://www.screentec.com/index.html Acesso em: 08 de jun.

(SELENIUM, 2006). Selenium. Características do tweeter ST300 da Selenium, 2006. Disponível em: 〈http://www.partsexpress.com/pdf/264-355.pdf Acesso em: 20 de jun. 
(SESSLER, 1987). Sessler, G. M. Electrets, chapter 1, pages 1-6. Springer-Verlag, New York Berlin Heidelberg, 1987.

(TEKTRONIX, 2006). Tektronix. Manual do osciloscópio TDS-210, 2006. Disponível em: 〈http://www.tektronix.com/ Acesso em: 20 de jun.

(THINKSRS, 2006). Thinksrs. Manual do Lock-in amplifier SR510, 2006. Disponível em: /http://www.thinksrs.com/products/SR510530.htm/ Acesso em: 20 de jun.

(TRAINER, 2003). Trainer, M. Kelvin and piezoelectricity. IEEE Transactions on Dielectric and Electrical Insulation, 10:842-861, 2003.

(WADA \& HAYAKAWA, 1976). Wada, Y. e Hayakawa, R. Piezoelectricity and Pyroelectricity of Polymer. Japanese Journal of Applied Physics, 15(11):2041-2057, 1976.

(WEINHOLD et al., 2000). Weinhold, T., SeiB, M., Künstler, W., Görne, T., e GerhardMulthaupt, R. Porous polytetrafluoroethylene (PTFE) single-film space-charge electrets with high piezoelectric coefficients. Dielectric Materials, Measurements and Applications, Conference Publication, pages 380-385, 2000.

(ZHANG et al., 2006). Zhang, X., Hillenbrand, J., e Sessler, G. M. Thermally stable fluorocarbon ferroelectrets with high piezoelectric coefficient. Journal of Applied Physics, Online First, 2006. 


\section{Apêndice A}

\section{A.1 Teoria do microfone de eletreto}

A figura A.1 representa um modelo estrutural de um microfone de eletreto, contendo um dielétrico com uma única camada de cargas elétricas com densidade $\sigma$, a uma localização $x=\bar{r}$ (SESSLER, 1987).

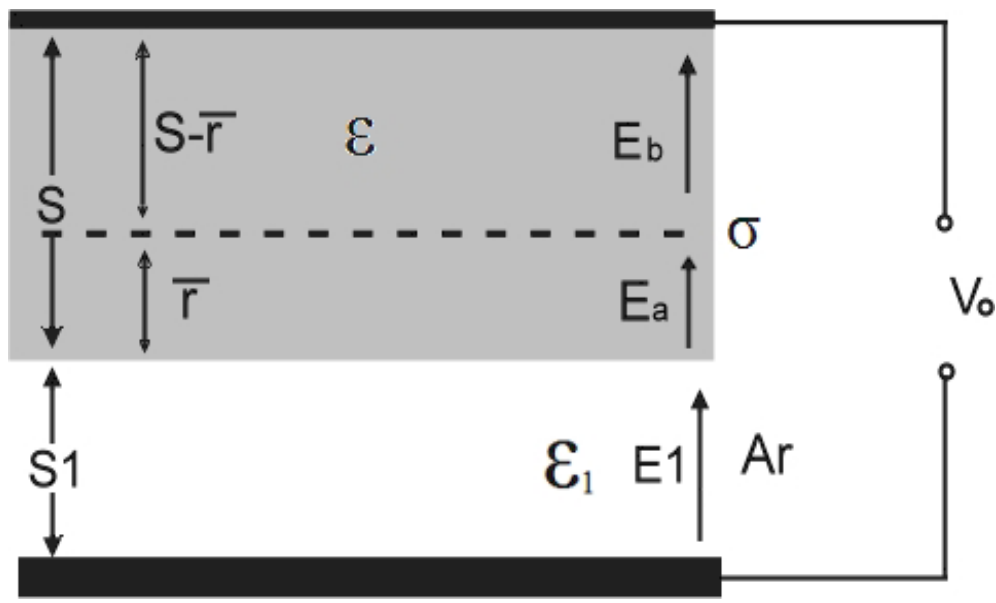

Figura A.1: Representação esquemática do microfone de eletreto.

Nesta figura estão representados os campos elétricos $E_{1}, E_{a}$ e $E_{b}$, orientados conforme a figura A.1 por não se conhecer a distribuição das tensões elétricas. Também estão identificadas as permissividades relativas do ar $\epsilon_{1}$ e do dielétrico $\epsilon$, e suas espessuras $S_{1}$ e $S$.

Ao aplicar a lei de Gauss nesse modelo obtem-se:

$$
-\epsilon_{1} E_{1}+E_{a} \epsilon=0 \Longrightarrow E_{a}=\begin{gathered}
\epsilon_{1} E_{1} \\
\epsilon
\end{gathered}
$$




$$
-\epsilon E_{a}+\epsilon E_{b}={ }_{\epsilon_{0}}^{\sigma} \Longrightarrow E_{b}={ }_{\epsilon_{0} \epsilon}^{\sigma}+{ }_{\epsilon} E_{1}
$$

Pela segunda Lei de Kirchhoff pode-se estabelecer que:

$$
V_{0}+E_{1} S_{1}+E_{a} \bar{r}+E_{b}(S-\bar{r})=0
$$

Substituindo $E_{a}$ por A.1 e $E_{b}$ por A.2 na equação A.3 obtem:

$$
\begin{aligned}
& V_{0}+E_{1} S_{1}+{ }_{\epsilon}^{\epsilon_{1} E_{1}} \bar{r}+\left(\begin{array}{c}
\sigma \\
\epsilon_{0} \epsilon
\end{array}+\begin{array}{c}
\epsilon_{1} E_{1} \\
\epsilon
\end{array}\right)(S-\bar{r})=0 \\
& V_{0}+E_{1} S_{1}+{ }_{\epsilon}^{\epsilon_{1} E_{1}} \bar{r}+{ }_{\epsilon_{0}}{ }^{\sigma}(S-\bar{r})+{ }_{\epsilon}^{\epsilon_{1} E_{1}} S-{ }_{\epsilon}^{\epsilon_{1} E_{1}} \bar{r}=0 \\
& \left.V_{0}+E_{1} S_{1}+{ }_{\epsilon_{0}} \epsilon \text { (S- }\right)+{ }_{\epsilon}^{\epsilon_{1} E_{1}} S=0
\end{aligned}
$$

Ao multiplicar todos os termos por ${ }_{\epsilon}^{1}$ obtem-se:

$$
\begin{aligned}
& { }_{\epsilon_{1}}^{V_{0}}+{ }_{\epsilon_{1}}^{E_{1} S_{1}}+{ }_{\epsilon_{0} \epsilon \epsilon_{1}}^{\sigma}(S-\bar{r})+{ }_{\epsilon}^{E_{1}} S=0 \\
& { }_{\epsilon_{1}}^{V_{0}}+E_{1}\left(\begin{array}{l}
S_{1} \\
\epsilon_{1}
\end{array}+\begin{array}{l}
S \\
\epsilon
\end{array}\right)+\underset{\epsilon_{0} \epsilon \epsilon_{1}}{\sigma}(S-\bar{r})=0
\end{aligned}
$$

Para

$$
\begin{aligned}
& L=\left(\begin{array}{l}
S_{1} \\
\epsilon_{1}
\end{array}+\begin{array}{l}
S \\
\epsilon
\end{array}\right) \\
& V_{0}+E_{1} L+\underset{\epsilon_{0} \epsilon \epsilon_{1}}{\sigma}(S-\bar{r})=0
\end{aligned}
$$

Como $\bar{r} \cong 0$

$$
{ }_{\epsilon_{1}}^{V_{1}}+E_{1} L+\underset{\epsilon_{0} \epsilon \epsilon_{1}}{\sigma} S=0
$$

Para situação de curto circuito pode-se escrever $V_{0}=0$ assim, tem-se:

$$
E_{1}=-\begin{gathered}
\sigma S \\
\epsilon_{0} \epsilon \epsilon_{1} L
\end{gathered}
$$


Logo, para $\hat{V}=-E_{1} \hat{S}$ onde $\hat{S}$ é a deflexão do transdutor.

$$
\begin{gathered}
\hat{V}=\begin{array}{c}
\sigma S \hat{S} \\
\epsilon_{0} \epsilon \epsilon_{1}\left(\begin{array}{l}
S_{1} \\
\epsilon_{1}
\end{array}+\begin{array}{c}
S \\
\epsilon
\end{array}\right)
\end{array} \\
\hat{V}=\begin{array}{c}
\sigma S \hat{S} \\
\epsilon_{0}\left(S_{1} \epsilon+S \epsilon_{1}\right)
\end{array}
\end{gathered}
$$

E como a permissividade do ar $\epsilon_{1}=1$, tem-se:

$$
\hat{V}=\begin{gathered}
\sigma S \hat{S} \\
\epsilon_{0}\left(S_{1} \epsilon+S\right)
\end{gathered}
$$

\section{A.2 Curvas de ponderação em freqüência do decibelímetro}

A indicação da pressão sonora em decibel seria suficiente se a sensibilidade humana fosse independente da freqüência, mas isso não ocorre. Por exemplo: um som de $100 \mathrm{~dB}$ a uma freqüência de $100 \mathrm{~Hz}$ é percebido de forma menos intensa que um de 100 dB a $1000 \mathrm{~Hz}$. Para compensar as variações de sensibilidade com a freqüência, foram criadas curvas padrões (A, B, C e D) conforme gráfico da figura A.2.

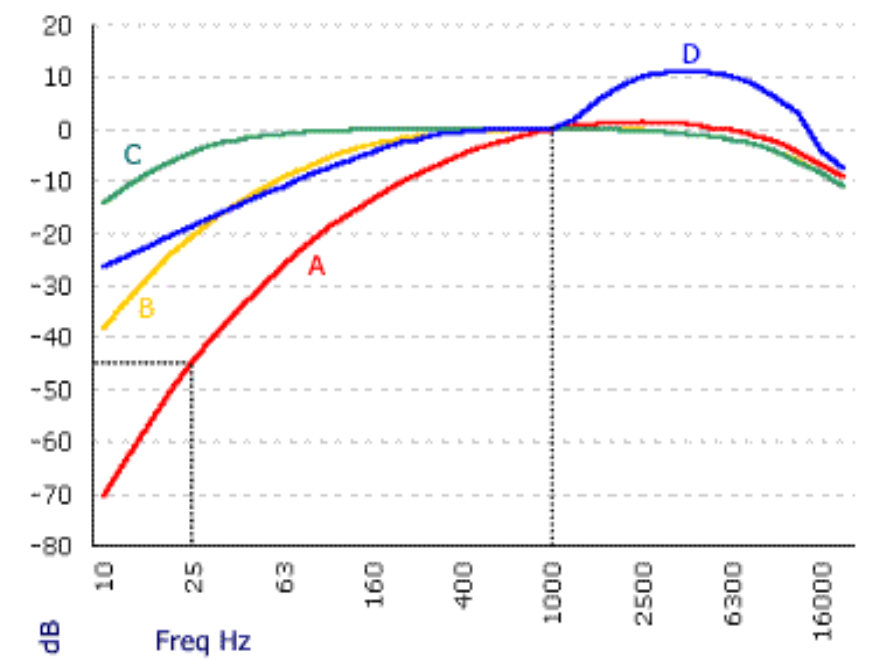

Figura A.2: Curvas de ponderação em freqüência.

Os valores em decibéis indicam as atenuações em relação à freqüência de 
referência de $1000 \mathrm{~Hz}$ e os dados atenuados são indicados por dB seguido da letra da curva correspondente (dBA, dBB, etc).

As fontes sonoras usuais não emitem uma única freqüência, na realidade são espectros em uma determinada faixa. Os instrumentos que medem pressão sonora (popularmente chamados de decibelímetros) fazem uma correção ponderada de acordo com as freqüências predominantes do espectro para dar um resultado na curva desejada. 